\title{
Loss of Activity-Induced Mitochondrial ATP Production Underlies the Synaptic Defects in a Drosophila model of ALS
}

\author{
Nicholas E. Karagas ${ }^{1,6,9}$, Kai Li Tan ${ }^{3,4,5,10}$, Hugo J. Bellen ${ }^{3,4,5}$, Kartik \\ Venkatachalam ${ }^{1,6,7,11}$, and Ching-On Wong ${ }^{8,11}$
}

${ }^{1}$ Department of Integrative Biology and Pharmacology, McGovern Medical School at the University of Texas Health Sciences Center (UTHealth), Houston, TX 77030, USA

${ }^{3}$ Departments of Molecular and Human Genetics and Neuroscience

${ }^{4}$ Graduate Program in Developmental Biology, Baylor College of Medicine, Houston, TX 77030, USA

${ }^{5}$ Duncan Neurological Research Institute, Texas Children Hospital, Houston, TX 77030, USA

\section{${ }^{6}$ Graduate Program in Biochemistry and Cell Biology}

MD Anderson Cancer Center and UTHealth Graduate School of Biomedical Sciences

$$
{ }^{7} \text { Graduate Program in Neuroscience }
$$

MD Anderson Cancer Center and UTHealth Graduate School of Biomedical Sciences

${ }^{8}$ Department of Biological Sciences, Rutgers University, Newark, NJ 07102, USA

${ }^{9}$ Present address: Department of Neurology, University of Washington, Seattle, WA 98195, USA

${ }^{10}$ Present address: Emergent BioSolutions, Gaithersburg, MD 20879, USA

${ }^{11}$ Correspondence: kartik.venkatachalam@uth.tmc.edu, chingon.wong@rutgers.edu 


\section{Abstract}

Mutations in the gene encoding VAPB (vesicle-associated membrane protein B) cause a familial form of Amyotrophic Lateral Sclerosis (ALS). Expression of an ALS-related variant of vapb $\left(\right.$ vaph $\left.^{P 58 S}\right)$ in Drosophila motor neurons results in morphological changes at the larval neuromuscular junction (NMJ) characterized by the appearance of fewer, but larger, presynaptic boutons. Although diminished microtubule stability is known to underlie these morphological changes, a mechanism for the loss of presynaptic microtubules has been lacking. Here, we demonstrate the suppression of vaph ${ }^{P 58 S}$. induced changes in NMJ morphology by either the loss of $\mathrm{ER} \mathrm{Ca}^{2+}$ release channels or the inhibition $\mathrm{Ca}^{2+} /$ calmodulin (CaM)-activated kinase II (CaMKII). These data suggest a model in which decreased stability of presynaptic microtubules at $v a p b^{P 58 S}$ NMJs result from hyperactivation of CaMKII due to elevated cytosolic $\left[\mathrm{Ca}^{2+}\right]$. We attribute the $\mathrm{Ca}^{2+}$ dyshomeostasis to delayed extrusion of cytosolic $\mathrm{Ca}^{2+}$ stemming from a paucity of activity-induced mitochondrial ATP production coupled with elevated rates of ATP consumption. Taken together, our data point to bioenergetic dysfunction as the root cause for the synaptic defects in vaph ${ }^{P 58 S}$-expressing Drosophila motor neurons. 


\section{Significance Statement}

Rates of ATP production and consumption are tightly synchronized in healthy neurons. Whether this synchrony is lost in models of neurodegenerative diseases remains poorly understood. Here, we find that expression of a gene encoding an ALS-causing variant of an ER membrane protein, VAPB, decouples mitochondrial ATP production from neuronal activity. Due to a combination of diminished ATP production and elevated ATP consumption - established outcomes in ALS neurons - the levels of ATP in vaph ${ }^{\text {P58S }}$ neurons are unable to keep up with the bioenergetic burden of depolarization. The resulting paucity of ATP and attendant decrease in the activity of $\mathrm{Ca}^{2+}$ ATPases results in diminished extrusion of cytosolic $\mathrm{Ca}^{2+}$ in $v \mathrm{apb}^{P 58 S}$-expressing motor neurons. The accumulation of residual $\mathrm{Ca}^{2+}$ in $v a p b^{P 58 S}$-expressing neurons underlies paired-pulse facilitation of synaptic vesicle release, and the changes in bouton development at the NMJ. In summary, our findings point to bioenergetic dysfunction due to the loss of activity-induced ATP production as being the cause of the synaptic defects observed in a Drosophila model of ALS.

\section{Keywords}

Drosophila neurobiology; neurodegeneration; ALS; VAPB; ER $\mathrm{Ca}^{2+}$ signaling; mitochondrial ATP production; activity-induced ATP production; neuronal bioenergetics 


\section{Introduction}

ALS is an untreatable neurodegenerative disease characterized by the progressive loss of motor function leading to paralysis and death by respiratory failure (Taylor et al., 2016). Mutations in many genes have been implicated in the onset of the familial forms of the disease, which result in one or more of the following - disrupted nucleocytoplasmic transport, proteostatic imbalance, alterations in RNA metabolism, genome instability, mitochondrial dysfunction, aberrant $\mathrm{Ca}^{2+}$ homeostasis, neuronal hyperexcitability, and neuroinflammation (Ling et al., 2013; Selfridge et al., 2013; Taylor et al., 2016; Lin et al., 2017; Frere and Slutsky, 2018). In this study, we sought to examine the mechanisms of neuronal dysfunction in flies expressing a missense variant of vapb, which is equivalent to the human variant that causes a familial form of ALS (ALS8) in humans (Nishimura et al., 2004, 2005; Kanekura et al., 2006; Marques et al., 2006; Landers et al., 2008; Borgese et al., 2021). We chose VAPB because of the importance of this protein to neuronal viability. In addition to the missense variant that functions via a dominant-negative mechanism (Ratnaparkhi et al., 2008), spinal cords from patients with sporadic cases of ALS exhibit decreased VAPB expression (Anagnostou et al., 2010; Mitne-Neto et al., 2011). Defective VAPB function is also observed in Parkinson's disease (Kun-Rodrigues et al., 2015; Paillusson et al., 2017; Boczonadi et al., 2018).

At the molecular level, VAPB is a single-pass ER membrane protein that has been proposed to regulate mTOR signaling, autophagy, lysosomal acidification, proteasomal degradation and ER quality control, and formation of interorganellar contacts that link 
the ER to endosomes, peroxisomes, Golgi, and mitochondria (Peretti et al., 2008; De Vos et al., 2012; Deivasigamani et al., 2014; Moustaqim-Barrette et al., 2014; Roulin et al., 2014; Dong et al., 2016; Stoica et al., 2016; Hua et al., 2017; Zhao et al., 2018; Chaplot et al., 2019; Mao et al., 2019; Şentürk et al., 2019; Borgese et al., 2021). By promoting the formation of ER-mitochondria contacts, VAPB also mediates the transfer of $\mathrm{Ca}^{2+}$ from ER into the mitochondrial matrix, and thereby, regulates ATP synthesis (De Vos et al., 2012; Stoica et al., 2016; Gomez-Suaga et al., 2017; Smith et al., 2017; Xu et al., 2020; Borgese et al., 2021; Wong et al., 2021).

Expression of the ALS-related variants of vapb in Drosophila neurons have been shown to result in morphological alterations in both axons and dendrites (Chai et al., 2008; Ratnaparkhi et al., 2008; Kamemura et al., 2021). Although it is known that defects in the development of the axon termini stem from diminished stability of presynaptic microtubules (Chai et al., 2008; Ratnaparkhi et al., 2008), exactly how mutant VAPB disrupts the microtubule cytoskeleton has remained unknown. In order to uncover the underlying molecular mechanism, we sought to examine genetic interactions between the vapb variant and genes encoding $\mathrm{ER} \mathrm{Ca}{ }^{2+}$ channels whose absence elicits phenotypes that ostensibly resemble those evoked by mutant vapb (Wong et al., 2014). These studies revealed that the phenotypes arising from the expression of mutant vapb are a consequence of presynaptic $\mathrm{Ca}^{2+}$ dyshomeostasis due to the inability of the neurons to maintain the levels of ATP needed for ensuring $\mathrm{Ca}^{2+}$ extrusion. Our findings agree with the insights gleaned from in silico modeling of ALS neurons (Le Masson et al., 2014), and provide an overarching explanation for the 
bioRxiv preprint doi: https://doi.org/10.1101/2021.12.14.472444; this version posted December 16, 2021. The copyright holder for this preprint (which was not certified by peer review) is the author/funder. All rights reserved. No reuse allowed without permission.

presynaptic defects associated with the expression of the ALS-causing variant of vapb in Drosophila motor neurons. 


\section{Results}

\section{Expression of an ALS-related variant of vapb results in defective presynaptic}

\section{bouton development}

Either the deletion of Drosophila vapb (also called Vap33) or the expression of a transgene equivalent to an ALS-causing variant $\left(\operatorname{vapb}^{P 58 S}\right)$ disrupts presynaptic microtubules at the larval NMJ resulting in the appearance of fewer, but morphologically larger, boutons (Pennetta et al., 2002; Chai et al., 2008; Ratnaparkhi et al., 2008). We confirmed that ectopic expression of $v a p b^{P 58 S}$, but not wild-type $\operatorname{vapb}\left(\operatorname{vaph}^{W T}\right)$, in motor neurons (using VGlut ${ }^{\text {tk371 }}$-GAL4, herein referred to as ok371-GAL4) led to a significant reduction in bouton number (Fig. 1A-E) (Brand and Perrimon, 1993; Mahr and Aberle, 2006; Tsuda et al., 2008). NMJ boutons in neurons expressing vapb ${ }^{P 58 S}$ also exhibited significant increases in bouton area (Fig. 1A-B and 1F). Direct comparison with animals expressing $v a p b^{W T}$ revealed that those expressing $v a p b^{P 58 S}$ exhibited significantly fewer and larger boutons (Fig. 1E-F). These data agree with prior findings regarding the effects of VAPB ${ }^{\mathrm{P} 58 \mathrm{~S}}$ on Drosophila larval NMJ synapse morphology (Chai et al., 2008; Ratnaparkhi et al., 2008).

\section{$\mathrm{VAPB}^{\mathrm{P} 58 \mathrm{~S}}$-induced defects in presynaptic bouton development are ameliorated by lowering the expression of genes encoding $\mathrm{ER} \mathrm{Ca}^{2+}$ release channels}

We previously showed that decreased abundance of $\mathrm{ER} \mathrm{Ca}^{2+}$ release channels Inactive (lav), ryanodine receptor $(\mathrm{Ry} R)$, and inositol trisphosphate receptor $\left(\mathrm{IP}_{3} \mathrm{R}\right)-$ result in NMJs that exhibit fewer boutons that are larger in size (Fig. 2A) (Wong et al., 2014). This implied ostensible similarities between the morphology of NMJ boutons in 
iav ${ }^{1}$ mutants (also called iav $v^{\text {hypoB-1 }}$ — strong hypomorphs of iav (Homyk and Sheppard, 1977; Wong et al., 2014)) and animals expressing vapb ${ }^{P 58 S}$. Therefore, we speculated that the coincidence of $i a v^{1}$ and $v a p b^{P 58 S}$ would enhance the respective phenotypes leading to an even greater reduction in bouton number (Fig. 2A). To our surprise, expression of $v a p b^{P 58 S}$ in the iav ${ }^{1}$ background restored, rather than worsened, both bouton number and morphology to control levels (Fig. 2B-C and 2J-K). Whereas bouton numbers and area elicited by $\operatorname{vapb}^{P 58 S}$ were not significantly different from those in $\operatorname{iav}^{1}$, these parameters were restored to wild-type levels upon the coincidence of $v a p b^{P 58 S}$ and $\operatorname{iav}^{1}$ (Fig. 2J-K). In contrast, overexpression of $v a p b^{W T}$ did nothing to alter the paucity of boutons in $\operatorname{iav}^{1}$ (Fig. 2D-E and 2L). Therefore, decreased abundance of lav rescued the synaptic growth phenotype stemming from the expression of $v a p b^{P 58 S}$.

Next, we asked whether the rescue of $v a p b^{P 58 S}$-induced NMJ phenotypes was specific to the loss of lav, or whether similar suppression would occur in response to lowered abundance of other $\mathrm{ER} \mathrm{Ca}^{2+}$ channels. Simultaneous knockdown of the gene encoding the fly $\mathrm{IP}_{3} \mathrm{R}$ (itpr) using the d42-GAL4 motor neuron driver and a validated RNAi line (UAS-itpr $\left.{ }^{R N A i}\right)$ ameliorated the effect of $v a p b^{P 58 S}$ expression on bouton number (Fig. 2G and 2M) (Venkatesh and Hasan, 1997; Parkes et al., 1998; Wong et al., 2014, 2021). Absence of comparable suppression in animals coexpressing vaph ${ }^{\text {P58S }}$ and a neutral UAS transgene (UAS-Dcr1) (Fig. 2F and 2M) demonstrates that the suppression brought about by coexpression of $i t p r^{R N A i}$ was not due to GAL4 dilution stemming from the presence of a second UAS transgene. Concomitant absence of one copy of $\operatorname{Ry} R\left(R y R^{16} /+\right)$, which mimics the iav ${ }^{1} \mathrm{NMJ}$ growth phenotype, also prevented 
$v^{\text {vapb }}{ }^{P 58 S}$-induced alterations in bouton numbers (Fig. 2H-I and 2N) (Sullivan et al., 2000; Wong et al., 2014). Taken together, these data demonstrate that $\mathrm{VAPB}^{\mathrm{P58S}}$-induced defects in presynaptic bouton development are ameliorated by cell autonomous reduction in the expression of genes encoding $\mathrm{ER} \mathrm{Ca}^{2+}$ channels.

\section{CaMKII overactivation underlies alterations in presynaptic development in motor neurons expressing vapb ${ }^{P 58 S}$}

The aforementioned findings are consistent with the notion of $\mathrm{VAPB}^{\mathrm{P} 58 \mathrm{~S}}$ inducing an increase in cytosolic $\left[\mathrm{Ca}^{2+}\right]$ such that the attenuation of $\mathrm{ER} \mathrm{Ca}{ }^{2+}$ release restores homeostasis, and thus, mitigates the bouton development phenotypes. Our data also imply that either an increase or decrease in presynaptic $\left[\mathrm{Ca}^{2+}\right]$ results in morphologically identical bouton phenotypes. Indeed, we previously showed that either the absence or overexpression of iav results in comparable reduction in the number of NMJ boutons (Wong et al., 2014). How might this bell-shaped relationship between presynaptic [Ca $\left.{ }^{2+}\right]$ and NMJ bouton development come about?

We posit that the key to understanding these outcomes is the phosphorylation status of the Drosophila microtubule-associated protein-1b homolog, Futsch — an important determinant of presynaptic microtubule stability and NMJ bouton morphology (Hummel et al., 2000; Wong et al., 2014). While dephosphorylated Futsch binds and stabilizes presynaptic microtubules, phosphorylated Futsch dissociates from microtubules leading to depolymerization of those cytoskeletal filaments (Fig. 3A). Results from many groups are consistent with either the hyperphosphorylation or absence of Futsch leading to a 
loss of presynaptic microtubules, increased bouton size, and decreased bouton number (Roos et al., 2000; Pennetta et al., 2002; Gögel et al., 2006; Viquez et al., 2006; Wong et al., 2014). Of relevance to the present study, the phosphorylation status of Futsch appears to depend on cytosolic $\left[\mathrm{Ca}^{2+}\right]$. Reduction in presynaptic resting $\left[\mathrm{Ca}^{2+}\right]$ and the attendant attenuation of the $\mathrm{Ca}^{2+} /$ calmodulin (CaM) responsive phosphatase, calcineurin (CanA1), destabilize presynaptic microtubules in a Futsch-dependent manner (Wong et al., 2014). In principle, increased activity of a $\mathrm{Ca}^{2+}$-responsive kinase could also result in hyperphosphorylated Futsch. If so, one may expect that either an increase or decrease in cytosolic $\left[\mathrm{Ca}^{2+}\right]$ would result in higher fractions of phosphorylated Futsch, and thus, microtubule depolymerization (Fig. 3A).

Putative increase in Futsch phosphorylation has been linked to the loss of Futsch loops within presynaptic boutons (Viquez et al., 2006; Wong et al., 2014). Motor neurons expressing vapb ${ }^{P 58 S}$ also exhibited fewer Futsch loops within presynaptic boutons (Fig. 3B-C). Since activation of the $\mathrm{Ca}^{2+} / \mathrm{CaM}-d e p e n d e n t$ protein kinase II (CaMKII or CKII) by high $\left[\mathrm{Ca}^{2+}\right]$ destabilizes microtubules by phosphorylating microtubule-associated proteins (Baratier et al., 2006; McVicker et al., 2015; Oka et al., 2017), we asked whether elevated $\mathrm{ER} \mathrm{Ca}^{2+}$ release compels the changes in NMJ development due to unrestrained CaMKII activity. Coexpression of the CaMKII inhibitory peptide, CaMKII ${ }^{\text {ala }}\left(\right.$ CKII $\left.^{\text {ala }}\right)$ (Joiner MIA and Griffith, 1997), with vapb ${ }^{P 58 S}$ led to recovery of the numbers of Futsch loops (Fig. 3B-C) and boutons (Fig. 3D). In iav ${ }^{1}$ synapses, which exhibit lower resting $\left[\mathrm{Ca}^{2+}\right]$ (Wong et al., 2014), expression of $C K I I^{a l a}$ did not restore the bouton number (Fig. 3D). Indicating the sufficiency of CaMKII downstream of 
elevated $\left[\mathrm{Ca}^{2+}\right]$, in iav-overexpressing neurons, which exhibit higher presynaptic $\left[\mathrm{Ca}^{2+}\right]$ (Wong et al., 2014), bouton number was restored to wild-type level upon coexpression of $C K I I^{a l a}$ (Fig. 3E). Taken together, these data suggest that vapb ${ }^{P 58 S}$-induced alterations in presynaptic development stem from aberrant CaMKII activation.

In a recent study, we showed that expression of $v a p b^{P 58 S}$ in motor neurons shortens Drosophila lifespan via overactivation of PLC $\beta-I P_{3} R$ signaling (Wong et al., 2021). Consequently, either the deletion of the gene encoding a fly PLC $\beta$ (norpA) or the concomitant knockdown of itpr in neurons expressing $v a p b^{P 58 S}$ strongly suppressed the effects of VAPB ${ }^{\text {P58S }}$ on animal longevity (Bloomquist et al., 1988; Wong et al., 2021). In contrast to the ameliorative effects on the NMJ bouton phenotype, neither $\operatorname{iav}^{1}$ nor the $R y R^{16} /+$ mutations influenced the lifespan of animals expressing vapb ${ }^{P 58 S}$ (Wong et al., 2021). Therefore, the effects of $v a p b^{P 58 S}$ on NMJ bouton development and adult lifespan occur via distinct mechanisms. In agreement, coexpression of $C K I I^{a l a}$, which mitigated the NMJ growth phenotype in animals expressing $v a p b^{P 58 S}$, did not influence the effect of mutant VAPB on adult lifespan (Fig. 3F).

\section{Expression of vapb $^{P 58 S}$ results in diminished extrusion of cytosolic $\mathrm{Ca}^{2+}$}

Lower presynaptic resting $\left[\mathrm{Ca}^{2+}\right]$ in the absence of lav results in reduced probability of synaptic vesicle (SV) release (Wong et al., 2014). NMJs in $\operatorname{iav}^{1}$ animals, therefore, exhibit reduced amplitudes of evoked excitatory postsynaptic junctional potentials (EJPs) and paired-pulse facilitation in response to a $2^{\text {nd }}$ stimulus applied after a delay of 50 milliseconds (Wong et al., 2014). Conversely, overexpression of iav led to an 
increase in presynaptic resting $\left[\mathrm{Ca}^{2+}\right]$, higher EJP amplitudes, and paired-pulse depression indicating elevated SV release probability (Wong et al., 2014). These data point to a dose-dependent effect of $\mathrm{ER} \mathrm{Ca}^{2+}$ release on presynaptic resting $\left[\mathrm{Ca}^{2+}\right]$ and SV release probability. Given that the NMJ bouton phenotypes in animals overexpressing either vapb ${ }^{P 58 S}$ or iav were suppressed by $\mathrm{CKII}{ }^{\text {ala }}$, we asked whether $\mathrm{VAPB}^{\mathrm{P} 58 \mathrm{~S}}$ also elevates SV release probability due to an increase in resting $\left[\mathrm{Ca}^{2+}\right]$. If so, expression of vapb ${ }^{P 58 S}$ would result in increased EJP amplitude and paired-pulse depression. However, EJP amplitudes in vapb ${ }^{P 58 S}$ neurons were not significantly different from those in $v a p b^{W T}$ neurons (Fig. 4A-B), which is in agreement with the report that ectopic expression of the ALS-causing human transgene ( $h V A P^{P 56 S}$ ) had no effect on the amplitude of evoked potentials at the Drosophila larval NMJ (Chai et al., 2008). Furthermore, relative to neurons expressing $v a p b^{W T}$, those expressing $v a p b^{P 58 S}$ showed paired-pulse facilitation, rather than paired-pulse depression (Fig. 4A and 4C). Amplitudes of mini-EJPs (mEJPs) and quantal content were also virtually identical in $v a p b^{W T}$ - and $v a p b^{P 58 S}$-expressing NMJs (Fig. 4D-E). Taken together, these data argue against elevations in presynaptic resting $\left[\mathrm{Ca}^{2+}\right]$ and SV release probability in vapb ${ }^{P 58 S_{-}}$ expressing motor neurons.

What then could explain the hallmarks of elevated $\left[\mathrm{Ca}^{2+}\right]$ in vapb ${ }^{P 58 S}$-expressing motor neurons? Elevations in cytosolic $\left[\mathrm{Ca}^{2+}\right]$ could stem either from greater $\mathrm{Ca}^{2+}$ influx or from diminished $\mathrm{Ca}^{2+}$ extrusion from the cytosol. Since the former is ruled out by the aforementioned data, we asked whether the effects of VAPB ${ }^{\mathrm{P} 58 \mathrm{~S}}$ stem from diminished $\mathrm{Ca}^{2+}$ extrusion (Fig. 4F). We reasoned that diminished $\mathrm{Ca}^{2+}$ extrusion would promote 
the accumulation of residual $\mathrm{Ca}^{2+}$, boost $\mathrm{SV}$ release in response to rapidly delivered stimuli, and thereby, explain the paired-pulse facilitation in vapb ${ }^{P 58 S}$-expressing neurons (Fig. 4A and 4C). To examine the rates of $\mathrm{Ca}^{2+}$ extrusion, we performed live-cell imaging of larval motor neurons expressing GCaMP5G-tdTomato (Daniels et al., 2014; Wong et al., 2014, 2021). To ensure that our assessment of $\mathrm{Ca}^{2+}$ extrusion focuses on transfer to the extracellular medium rather than uptake into the $\mathrm{ER}$, we applied the SERCA inhibitor, thapsigargin (TG) (Lytton et al., 1991; Wong et al., 2021). Incidentally, TG-treatment evokes cytosolic $\mathrm{Ca}^{2+}$ transients due to leak of ER stores into the cytosol (Wong et al., 2021), and the kinetics of the return of these transients to baseline reflect the rate of $\mathrm{Ca}^{2+}$ extrusion. We found that the decay of TG-evoked GCaMP5G-tdTomato elevations followed a $1^{\text {st }}$ order exponential function (Fig. 4G). Half-life of this decay was significantly higher in neurons expressing vapb ${ }^{P 58 S}$ compared to those expressing $v a p b^{W T}$ (Fig. 4G). These data argue in favor of diminished $\mathrm{Ca}^{2+}$ extrusion in neurons expressing vapb ${ }^{P 58 S}$.

\section{Rates of ATP production are unable to keep up with demand in vapb ${ }^{\text {P58S }}$. expressing motor neurons}

Electrochemical homeostasis in healthy neurons is maintained by pumps powered by mitochondrially-derived ATP. While SERCA and PMCA restore depolarization-induced changes in cytosolic $\left[\mathrm{Ca}^{2+}\right]$ to resting levels, the $\mathrm{Na}^{+} / \mathrm{K}^{+}$ATPase restores the membrane potential (Fergestad et al., 2006; Chouhan et al., 2012; Ivannikov and Macleod, 2013;

Le Masson et al., 2014). The purported coupling of ATP production to neuronal activity, therefore, ensures the availability of ATP for maintenance of $\mathrm{Ca}^{2+}$ homeostasis and for 
membrane repolarization (Fig. 5A, left) (Le Masson et al., 2014; Rangaraju et al., 2014; Wong et al., 2021). In ALS neurons, defects in mitochondrial function are predicted to result in a paucity of ATP, which in turn, attenuates the activity of $\mathrm{Ca}^{2+}$ - and $\mathrm{Na}^{+} / \mathrm{K}^{+}$ ATPases (Fig. 5A, right) (Le Masson et al., 2014). In silico modeling has revealed that the outcome of mitochondrial dysfunction and diminished pump activity is a "deadly loop" comprised of a rapidly burgeoning demand for ATP that remains unmet, and $\mathrm{Ca}^{2+}$ dyshomeostasis (Fig. 5A, right) (Le Masson et al., 2014). Since our findings of diminished $\mathrm{Ca}^{2+}$ extrusion in neurons expressing vapb ${ }^{P 58 S}$ (Fig. 4G) align with the notion of $\mathrm{Ca}^{2+}$ dyshomeostasis, we asked whether the expression of $v a p b^{P 58 S}-(1)$ compromises mitochondrial ATP production, and thereby, precludes a suitable response to the ATP burden of depolarization; and (2) increases the rates of overall ATP hydrolysis as inferred from in silico modeling of ALS neurons (Le Masson et al., 2014).

Given that mitochondrial $\mathrm{Ca}^{2+}$ uptake — needed for energizing those organelles and stimulating TCA dehydrogenases - is disrupted in $v a p b^{P 58 S}$-expressing neurons, it stood to reason that "on-demand" ATP production would be attenuated in these neurons (Duchen, 1992; McCormack and Denton, 1993; Dumollard et al., 2004; Cárdenas et al., 2010; Ding et al., 2018; Wong et al., 2021). To directly assess ATP production and consumption in neurons, we monitored the cytosolic $[\mathrm{ATP}] /[\mathrm{ADP}]$ ratio using the genetically-encoded sensor, PercevalHR (Tantama et al., 2013; Wong et al., 2021). In neurons coexpressing $v a p b^{W T}$, the PercevalHR ratio (i.e., the $[A T P] /[A D P]$ ratio) remained unchanged in response to depolarization by the application of high $\left[\mathrm{K}^{+}\right]$(52 
$\mathrm{mM}$ ) (Fig. 5B, blue trace - 1). These data, which agree with our prior findings in wildtype neurons (Wong et al., 2021), indicate that the rates of ATP production and consumption were perfectly balanced in $v a p b^{W T}$-expressing neurons following depolarization. In vaph ${ }^{P 58 S}$-expressing neurons, however, high $\left[\mathrm{K}^{+}\right]$led to a decline in the PercevalHR ratio (Fig. 5B, magenta trace - 1). Comparison of the integrated change in the PercevalHR ratio per unit time revealed a highly significant decrease from baseline in vapb $b^{P 58}$-expressing neurons, but a statistically insignificant change in $v a p b^{W T}$ neurons (Fig. 5C, high $\left[\boldsymbol{K}^{+}\right]$). Furthermore, the integrated drop in the PercevalHR ratio in vapb $b^{P 58 S}$ neurons was significantly greater than that in vapb $b^{W T}$ neurons (Fig. 5C, high $\left[\boldsymbol{K}^{+}\right]$). These data indicate that vapb ${ }^{P 58 S}$-expressing neurons were unable to maintain the $[A T P] /[A D P]$ ratio after depolarization, which pointed to enhanced ATP consumption and/or compromised response to the ATP burden of depolarization.

We previously showed that in vapb ${ }^{W T}$-expressing neurons, $I \mathrm{P}_{3} \mathrm{R}$ activation in response to muscarine-induced stimulation of PLC $\beta$-coupled acetylcholine receptors elevates mitochondrial $\left[\mathrm{Ca}^{2+}\right]$ as a consequence of interorganellar $\mathrm{Ca}^{2+}$ transfer (Wong et al., 2021). Consistent with reports of ALS-causing variants of VAPB disrupting interorganellar $\mathrm{Ca}^{2+}$ transfer, muscarine-evoked mitochondrial $\left[\mathrm{Ca}^{2+}\right]$ elevations were absent in vapb ${ }^{P 58 S}$-expressing neurons (De Vos et al., 2012; Stoica et al., 2016; GomezSuaga et al., 2017; Smith et al., 2017; Xu et al., 2020; Wong et al., 2021). Given the role for matrix $\left[\mathrm{Ca}^{2+}\right]$ in energizing mitochondria and promoting ATP production (Duchen, 1992; McCormack and Denton, 1993; Dumollard et al., 2004; Cárdenas et al., 2010; 
Ding et al., 2018), we reasoned that diminished interorganellar $\mathrm{Ca}^{2+}$ transfer would attenuate muscarine-induced ATP production in $v a p b^{P 58 S}$ neurons. Indeed, muscarine evoked a significantly smaller elevation in the $[\mathrm{ATP}] /[\mathrm{ADP}]$ ratio in $v a p b^{P 58 S}$ neurons than it did in neurons expressing vapb ${ }^{W T}$ (Fig. 5B, 2 and 5C, 1 mM muscarine). These data support the principle that diminished $\mathrm{Ca}^{2+}$ uptake into the mitochondrial matrix perturbs the rate of ATP production in $v a p b^{P 58 S}$-expressing neurons.

Subsequent inhibition of glycolysis by the application of 2-deoxyglucose (2-DG) did not affect the $[\mathrm{ATP}] /[\mathrm{ADP}]$ ratio in neurons expressing either vapb ${ }^{W T}$ or vapb ${ }^{P 58 S}$ (Fig. 5B, 3 and 5C, $10 \mathrm{mM}$ 2-DG). In contrast, inhibition of OXPHOS using the ATP synthase inhibitor, oligomycin A (oligoA), decreased the $[A T P] /[A D P]$ ratio in neurons expressing either vapb ${ }^{W T}$ or $v^{2} b^{P 58 S}$ (Fig. 5B, 4 and 5C, $10 \mu M$ oligoA). Therefore, the $[A T P] /[A D P]$ ratio in those neurons exhibited greater sensitivity to the inhibition of OXPHOS rather than glycolysis. The drops in the integrated PercevalHR ratio after inhibition of OXPHOS were comparable in the $v a p b^{W T}$ and $v a p b^{P 58 S}$ neurons (Fig. 5C, $10 \mu M$ oligoA). These data imply that upon the cessation of ATP production, the cumulative drop in the $[A T P] /[A D P]$ ratio is the same in neurons expressing either $v a p b^{W T}$ or $v a p b^{P 58 S}$. Therefore, the decline in the $[A T P] /[A D P]$ ratio in depolarized $v a p b^{P 58 S}$ neurons reflects changes in the rates of ATP synthesis and consumption rather than changes in ADP availability. In agreement, upon fitting the decay of the $[A T P] /[A D P]$ ratio to $1^{\text {st }}$ order exponential functions (Fig. 5D), we found that the $[\mathrm{ATP}] /[\mathrm{ADP}]$ ratio settles at comparable values in $\operatorname{vapb}^{W T}$ and $v a p b^{P 58 S}$ neurons (i.e., insignificant differences in plateau $/ Y_{0}$ values) (Fig. $5 E$ ). However, the rate of decay was 
significantly greater in $v a p b^{P 58 S}$, resulting in a shorter half-life (Fig. 5E). These data imply elevated rates of ATP consumption in vapb ${ }^{P 58}$-expressing Drosophila motor neurons.

\section{Loss of synaptic transmission during high-frequency stimulation in vapb ${ }^{P 58 S}$.}

\section{expressing motor neurons}

Many $\operatorname{vapb}^{P 58 S}$ phenotypes we describe in this study, including elevated cytosolic $\left[\mathrm{Ca}^{2+}\right]$ and ATP depletion, are also observed in drp1-deficient animals (Verstreken et al., 2005). Since the paucity of ATP in drp1 mutant NMJs precludes the maintenance of synaptic transmission during high-frequency stimulation (Verstreken et al., 2005), we asked whether the shortage of ATP in $v a p b^{P 58 S}$ motor neurons would result in similar rundown of SV release. Although stimulation of the vapb ${ }^{P 58 S} \mathrm{NMJs}$ at $10 \mathrm{~Hz}$ led to EJP amplitudes that initially plateaued at values that were $\sim 35 \%$ higher than baseline, those values transitioned to periods of sustained decay after $\sim 5$ minutes of high-frequency stimulation (Fig. 5F left, traces with filled circles, green arrow indicates onset of decay). EJP amplitudes in $100 \%$ of the traces recorded from vapb $b^{P 58}$ animals stimulated at 10 $\mathrm{Hz}$ exhibited sustained periods of decay after initial, transient elevations. We reasoned that superimposed on the liminal increase in EJP amplitudes were the rundowns of SV release, which become apparent after $\sim 5$ minutes of high-frequency stimulation. We extracted the rundown components from the traces using the rate-constants of the decay (Fig. 5F left, traces with filled squares). Over the 10-minute duration of the highfrequency stimulation, calculated rundowns in vapb ${ }^{P 58 S}$ NMJs dropped significantly lower than baseline (Fig. 5F, left). The decay phase of high-frequency traces recorded 
from vapb ${ }^{W T}$ NMJs was relatively less-pronounced (Fig. $5 F$, right), with only $40 \%$ of the traces exhibiting sustained periods of declining EJP values. Calculated rundown in $v a p b^{W T}$ NMJs was not significantly lower than baseline (Fig. 5F, right). Furthermore, calculated rundowns in $v^{2} b^{P 58 S}$ were predicted to plateau at $3.82 \mathrm{mV}(95 \% \mathrm{Cl}, 3.69$ to $3.94, P<0.0001)$, whereas rundowns were predicted to plateau at $11.96 \mathrm{mV}(95 \% \mathrm{Cl}$, 11.81 to $12.11, P<0.0001)$ in $v a p b^{W T}$. Taken together, these data indicate that highfrequency stimulation leads to a greater loss of synaptic transmission in vapb ${ }^{P 58 S_{-}}$ expressing motor neurons. 


\section{Discussion}

Our findings explain the characteristic changes to NMJ morphology observed in animals that harbor vapb deletions or express an ALS-causing variant $\left(v_{a p b}^{P 58 S}\right)$ of the gene (Pennetta et al., 2002; Chai et al., 2008; Ratnaparkhi et al., 2008). While it was known that the reduction in NMJ bouton number and the increase in bouton size in these animals stemmed from diminished stability of the presynaptic microtubules (Pennetta et al., 2002; Chai et al., 2008; Ratnaparkhi et al., 2008), the molecular underpinnings of these cytoskeletal changes had remained incompletely understood. Our findings that the morphological defects observed in $v a p b^{P 58 S}$ NMJs were attenuated by the coexpression of a peptide that inhibits CaMKII implicate the aberrant activation of this kinase in the appearance of these phenotypes. These conclusions agree with prior reports of CaMKII regulating microtubule stability by phosphorylating microtubuleassociated proteins (Baratier et al., 2006; McVicker et al., 2015; Oka et al., 2017).

We also present data that raise the possibility that the MAP1b homolog, Futsch (Hummel et al., 2000; Roos et al., 2000), could be the relevant CaMKIl target in this context. Previous studies have shown that hyperphosphorylation of Futsch, which provokes the destabilization of presynaptic microtubules, results in the loss of Futschloops within the NMJ boutons (Gögel et al., 2006; Viquez et al., 2006; Wong et al., 2014). Not only did the vapb ${ }^{P 58 S}$ NMJs exhibit fewer Futsch loops, these values were restored to wild-type levels upon the coexpression of the CaMKII inhibitory peptide. The involvement of Futsch in the phenotypes observed in this model of ALS are in agreement with prior reports of TDP-43-induced proteinopathy exhibiting reduced 
Futsch abundance at the NMJ due to diminished translation of its mRNA (Coyne et al., 2014). Therefore, multiple Drosophila models of ALS are associated with a decrease in microtubule stability stemming either from reduced Futsch abundance or due to hyperphosphorylation of the protein (Pennetta et al., 2002; Ratnaparkhi et al., 2008; Coyne et al., 2014). Interestingly, expression of a gain-of-function variant of vapb results in an increase in the number of synaptic boutons and number of Futsch loops (Sanhueza et al., 2014). Given the likelihood that VAPB ${ }^{\mathrm{P} 58 \mathrm{~S}}$ acts through a dominantnegative mode of action (Ratnaparkhi et al., 2008), there appears to be a direct correlation between the functionality/dosage of VAPB, Futsch-dependent microtubule stability, and bouton number at the Drosophila NMJ (Pennetta et al., 2002; Sanhueza et al., 2014).

Ectopic expression of an overactive TRPV4 channel variant that elevates intracellular $\left[\mathrm{Ca}^{2+}\right]$ leads to neuropathology via CaMKII hyperactivation (Woolums et al., 2020). Therefore, there is precedent for the notion that aberrant activation of CaMKII in motor neurons implies higher cytosolic $\left[\mathrm{Ca}^{2+}\right]$. Dampening sources of presynaptic $\mathrm{Ca}^{2+}$ elevation then would be expected to restore $\mathrm{Ca}^{2+}$ homeostasis, and thereby, ameliorate the consequences of CaMKII hyperactivation. Indeed, reduced expression of $\mathrm{ER} \mathrm{Ca}^{2+}$ release channels in Drosophila neurons counteracts the phenotypes stemming from activating mutations in a voltage-gated $\mathrm{Ca}^{2+}$ channel (Brusich et al., 2018). We found that lowering the abundance of any one of the three presynaptic $\mathrm{ER} \mathrm{Ca}^{2+}$ release channels - lav, RyR, and $I P_{3} R$ - restored bouton morphology and number in neurons expressing $v a p b^{P 58 S}$. These data also point to the existence of a biphasic, bell-shaped 
relationship between presynaptic $\left[\mathrm{Ca}^{2+}\right]$ and NMJ morphology, whereby either a supraphysiological increase or decrease in $\left[\mathrm{Ca}^{2+}\right]$ elicits morphologically indistinguishable changes at the NMJ. While a decrease in presynaptic resting $\left[\mathrm{Ca}^{2+}\right]$ results in Futsch hyperphosphorylation and microtubule destabilization due to diminished activity of the $\mathrm{Ca}^{2+} / \mathrm{CaM}$-responsive phosphatase, calcineurin, increased cytosolic $\left[\mathrm{Ca}^{2+}\right]$ also elicits Futsch hyperphosphorylation albeit via elevated CaMKII activity.

Given that the NMJ phenotypes in neurons expressing vapb ${ }^{P 58 S}$ were suppressed by the loss of $\mathrm{ER} \mathrm{Ca}^{2+}$ channels, which are needed for maintaining presynaptic resting $\left[\mathrm{Ca}^{2+}\right]$ (Wong et al., 2014), we asked whether VAPB ${ }^{\mathrm{P} 58 \mathrm{~S}}$ was triggering an increase in resting $\left[\mathrm{Ca}^{2+}\right]$. Higher presynaptic resting $\left[\mathrm{Ca}^{2+}\right]$ augments the probability of SV release resulting in increased amplitudes of evoked post-synaptic potentials that is accompanied by paired-pulse depression (Wong et al., 2014). However, in agreement with prior reports (Chai et al., 2008), we found that expression of vapb ${ }^{P 58 S}$ induced neither a change in the amplitude of evoked potentials nor the appearance of pairedpulse depression. Rather, vapb ${ }^{P 58 S}$ NMJs exhibited paired-pulse facilitation, which in combination with the absence of changes in the amplitude of evoked potentials, was consistent with post-stimulus accumulation of residual $\mathrm{Ca}^{2+}$ due to delayed extrusion of presynaptic $\mathrm{Ca}^{2+}$. Indeed, direct examination of cytosolic $\left[\mathrm{Ca}^{2+}\right]$ using GCaMP5GtdTomato revealed significantly delayed $\mathrm{Ca}^{2+}$ extrusion in vapb ${ }^{P 58 S}$-expressing motor neurons. These data indicate that the aberrant activation of CaMKII in vapb ${ }^{P 58 S}$ - 
expressing neurons arose from the accumulation of residual $\mathrm{Ca}^{2+}$ due to delayed extrusion.

What could explain the defects in $\mathrm{Ca}^{2+}$ extrusion in neurons expressing vapb ${ }^{\text {P58S }}$ ? The plasma membrane-resident $\mathrm{Ca}^{2+}$ ATPase, PMCA, has been shown to play a major role in the extrusion of presynaptic $\mathrm{Ca}^{2+}$ in Drosophila motor neurons (Ivannikov and Macleod, 2013; Rossano et al., 2013). Given the bioenergetic burden of powering PMCA, we postulated that a paucity of ATP could underlie the $\mathrm{Ca}^{2+}$ dyshomeostasis observed in vapb $b^{P 58}$-expressing neurons. In support of this model, mutated VAPB has been shown to disrupt interorganellar transfer of $\mathrm{Ca}^{2+}$ from the ER to mitochondria in both mammalian cells and Drosophila neurons (De Vos et al., 2012; Stoica et al., 2016; Gomez-Suaga et al., 2017; Smith et al., 2017; Xu et al., 2020; Wong et al., 2021). Given the role of matrix $\left[\mathrm{Ca}^{2+}\right]$ in ATP production (Duchen, 1992; McCormack and Denton, 1993; Dumollard et al., 2004; Cárdenas et al., 2010; Ding et al., 2018), we asked whether expression of $v a p b^{P 58 S}$ compromised mitochondrial ATP production. By examining the $[A T P] /[A D P]$ ratio in live neurons, we found that $A T P$ production was unable to match the demand of depolarization in $v a p b^{P 58 S}$-expressing neurons. Whereas the $[\mathrm{ATP}] /[\mathrm{ADP}]$ ratio in $v a p b^{W T}$-expressing neurons remained stable in response to depolarization, this ratio dropped precipitously in depolarized $v a p b^{P 58 S}$ neurons. The situation in vapb ${ }^{W T}$ neurons was akin to that in control Drosophila and mammalian neurons where the rates of ATP synthesis are exquisitely synchronized with its demand (Rangaraju et al., 2014; Wong et al., 2021). This synchrony was disrupted in $v a p b^{P 58 S}$ neurons. The drop in the $[\mathrm{ATP}] /[\mathrm{ADP}]$ ratio likely reflected a combination of 
diminished ATP synthesis and enhanced ATP consumption. Indeed, in silico modeling has predicted that mitochondrial dysfunction in ALS neurons is sufficient to induce a toxic self-reinforcing loop of increased ATP consumption and a progressive decrease in the availability of ATP (Le Masson et al., 2014). Taken together, our data are consistent with the model that the paucity of ATP levels in vaph ${ }^{P 58 S}$-expressing neurons during periods of neuronal activity result in diminished $\mathrm{Ca}^{2+}$ extrusion, which in-turn provokes hyperactivation of CaMKII and the attendant changes in NMJ morphology.

Maintenance of synaptic transmission at the Drosophila larval NMJs during periods of high-frequency stimulation depends upon a steady supply of ATP. A shortage of local ATP levels - for instance, due to an absence of presynaptic mitochondria in drp1 mutants - results in the rundown of SV release in response to high-frequency stimulation (Verstreken et al., 2005). These rundowns occur due to the inability of the synapses to meet the energy demands of SV cycling and diminished recruitment of the reserve pool of SVs that are otherwise mobilized to replace the rapid depletion of the readily-releasable pool of vesicles (Verstreken et al., 2005). In either the $v a p b^{W T}$ - or $v a p b^{P 58 S}$-expressing NMJs, high-frequency stimulation led to initial elevation of synaptic transmission. Superimposed over these liminal elevations were rundowns that became obvious after $\sim 5$ minutes of stimulation, and were significantly greater in vaph ${ }^{P 58 S}$. expressing neurons. These data agree with enhanced rundown of SV release in motor neurons expressing $v a p b^{P 58 S}$. The magnitude of this phenotype, however, was smaller than that observed in the drp1 mutants (Verstreken et al., 2005). This discrepancy may be explained by a steady-state decrease in ATP levels in drp1 mutant neurons 
(Verstreken et al., 2005), while $v a p b^{P 58 S}$-expressing neurons exhibit ATP insufficiency only during periods of heightened activity (Fig. 5).

In addition to the early changes in synapse development and function, expression of $v a p b^{P 58 S}$ also leads to adult-onset locomotor dysfunction and premature lethality (Wong et al., 2021). The findings presented here suggest that the neurodevelopmental and longevity phenotypes stem from partially overlapping, yet distinct, molecular pathways. While the NMJ phenotypes were suppressed by concomitant reductions in the abundance of lav and RyR, or by the expression of the CaMKII inhibitory peptide, none of these manipulations influenced the effects of $\mathrm{VAPB}^{\mathrm{P} 58 \mathrm{~S}}$ on adult lifespan. Only with the knockdown of the gene encoding $\mathrm{IP}_{3} \mathrm{Rs}$ do we observe suppression of both the NMJ development phenotypes and adult lethality, though the former involves the attenuation of CaMKII while the latter, as we showed previously, stems from the prevention of endolysosomal $\left[\mathrm{Ca}^{2+}\right]$ overload (Wong et al., 2021). 


\section{Acknowledgements}

We thank the Bloomington Drosophila Stock Center for fly stocks. We also thank Yufang Chao for technical help. Confocal and live cell microscopy was performed at the Center for Advanced Microscopy, Department of Integrative Biology \& Pharmacology at McGovern Medical School, UTHealth. This work was supported by the NIH grants RF1AG069076, RF1AG067414, and R21AG072176 (all to K.V.).

\section{Author Contributions}

C.W., N.E.K., K.L.T, and K.V. conducted the experiments. C.W., N.E.K., K.L.T, and K.V. analyzed the data. C.W., N.E.K., H.J.B., and K.V. conceived the experiments, and wrote the manuscript.

\section{Declaration of Interests}

The authors declare no competing interests. 


\section{Materials and Methods}

\section{Drosophila husbandry}

Flies were reared at $21^{\circ} \mathrm{C}$ on standard fly food ( $1 \mathrm{~L}$ of food contained: $95 \mathrm{~g}$ agar, $275 \mathrm{~g}$ Brewer's yeast, $520 \mathrm{~g}$ of cornmeal, $110 \mathrm{~g}$ of sugar, $45 \mathrm{~g}$ of propionic acid, and $36 \mathrm{~g}$ of Tegosept) unless otherwise stated. The following fly lines were obtained from Bloomington Drosophila Stock Center: ok371-GAL4 and d42-GAL4 (Parkes et al., 1998; Mahr and Aberle, 2006), $R y R^{16}$ (Sullivan et al., 2000), UAS-Dcr1 (Dietzl et al., 2007), UAS-CKII-I.Ala (UAS-CKIII/a) (Joiner MIA and Griffith, 1997), and UAS-itpr ${ }^{\text {RNAi }}$ (TRiP.JF01957) (Wong et al., 2021). Other strains used in the study were: UAS-vapb ${ }^{W T}$ and UAS-vaph ${ }^{P 58 S}$ (Tsuda et al., 2008), UAS-GCaMP5G-tdTomato (Wong et al., 2021), Canton-S, UAS-PercevalHR (Wong et al., 2021), $\operatorname{iav}^{1}$ (also called iav ${ }^{\text {hypoB-1}}{ }^{1}$ ) (Wong et al., 2014), and UAS-iav (Wong et al., 2014). Canton-S flies were used as the wild-type controls in the various crosses.

\section{NMJ immunohistochemistry and confocal microscopy}

Dissection and immunostaining of NMJ was performed as described previously (Wong et al., 2014, 2015). Briefly, wandering $3^{\text {rd }}$ instar larvae were filleted in ice-cold PBS to remove all visceral organs except the brain and nerves. The fillets were fixed in $4 \%$ paraformaldehyde in PBS for 30 minutes. The fixed fillets were washed with $0.1 \%$ Triton $\mathrm{X}-100$ in PBS before incubation with primary antibodies overnight at $4^{\circ} \mathrm{C}$. Primary antibody dilutions were 1:100 mouse anti-discs large (DLG) and 1:50 mouse antiFutsch. The monoclonal antibodies against DLG and Futsch were obtained from the Developmental Studies Hybridoma Bank developed under the auspices of the NICHD 
and maintained by The University of lowa, Department of Biology, lowa City, IA 52242. The samples were then washed and probed with 1:200 FITC-conjugated anti-HRP (Jackson ImmunoResearch) and Alexa Fluor 568-conjugated anti-mouse secondary antibodies (ThermoFisher) at room temperature for 1.5 hours, and then mounted on glass slides with Vectashield (Vector Labs). Confocal images were obtained using a Nikon A1 Confocal Laser Microscope System (Nikon). For NMJ bouton counting, a 60x oil objective was used to focus on the NMJs on abdominal segment 3.

\section{NMJ electrophysiology}

Wandering $3^{\text {rd }}$ instar larvae were dissected in ice-cold $\mathrm{HL}-3(70 \mathrm{mM} \mathrm{NaCl}, 5 \mathrm{mM} \mathrm{KCl}, 20$ $\mathrm{mM} \mathrm{MgCl} 2.6 \mathrm{H}_{2} \mathrm{O}, 10 \mathrm{mM} \mathrm{NaHCO}_{3}, 115 \mathrm{mM}$ sucrose, $5 \mathrm{mM}$ trehalose, and $5 \mathrm{mM}$ HEPES; $\mathrm{pH} 7.2$ ) and rinsed with $\mathrm{HL}-3$ containing $0.5 \mathrm{mM} \mathrm{Ca}^{2+}$. Recordings were made from body-wall muscle 6 (abdominal segment 3) with sharp electrodes filled with a 2:1 mixture of $2 \mathrm{M}$ potassium acetate and $2 \mathrm{M}$ potassium chloride. Data were collected from samples with resting membrane potential below $-60 \mathrm{mV}$. EJPs were evoked by directly stimulating the A3 hemisegmental nerve through a glass capillary electrode (internal diameter, $\sim 10 \mu \mathrm{m})$ at $0.2 \mathrm{~Hz}$. Stimulus pulses were generated by pClamp 10 software (Axon Instruments Inc). The applied currents were $6 \mu \mathrm{A} \pm 3$ with fixed stimulus duration at $0.3 \mathrm{~ms}$. Twenty to thirty evoked EJPs were recorded for each muscle for analysis. Miniature EJP ( $\mathrm{mEJP}$ ) events were collected for $5 \mathrm{~min}$. Both EJPs and mEJPs were amplified with an Axoclamp 900A amplifier (Axon Instruments, Foster City, CA) under bridge mode, filtered at $10 \mathrm{kHz}$ and digitized at $10 \mathrm{kHz}$ (EJPs) and $40 \mathrm{kHz}$ (mEJPs) with pClamp 10. Experiments were performed at $21^{\circ} \mathrm{C}$. EJPs and paired-pulse stimulation 
were analyzed with pClamp 8.0 software (Axon Instruments). The mEJPs were analyzed using the Mini Analysis Program (Synaptosoft Inc., Decatur, GA). The EJPs paired-pulse amplitudes were corrected by nonlinear summation (Feeney et al., 1998). Paired-pulse ratio was calculated as the ratio of $2^{\text {nd }}$ to $1^{\text {st }}$ peak. The quantal content of evoked release was calculated from individual muscles by the ratio of the average EJP amplitude over the average mEJP amplitude. For high-frequency stimulation, nerves were stimulated for 10 minutes at $10 \mathrm{~Hz}$. By fitting the decay portions of each highfrequency trace to a $1^{\text {st }}$-order exponential function, we obtained the rate-constant of decays. Rundowns were extracted from the rate-constants of decay. $\mathrm{Cl}$ of the calculated rundowns were determined by fitting the data calculated rundowns to $1^{\text {st }}$. order exponential functions in Prism 8. P-values for the confidence intervals $(\mathrm{Cl})$ were calculated as described (Altman and Bland, 2011).

\section{Dissociation of Drosophila neurons}

We dissociated primary motor neurons from Drosophila as described previously (Wong et al., 2021). Briefly, the exterior of wandering $3^{\text {rd }}$ instar larvae was sterilized by brief submersion in ethanol, and then washed with sterilized $\mathrm{H}_{2} \mathrm{O}$ before dissection in filtered Schneider's medium (S0146; Sigma-Aldrich) containing 10\% FBS, antibiotic/antimycotic solution (A5955; Sigma-Aldrich) and $50 \mu \mathrm{g} / \mathrm{ml}$ of insulin (16634; Sigma-Aldrich). Brains dissected from these larvae were washed in separate wells containing filtered Schneider's medium before being transferred to a filtered $\mathrm{HL}-3$ solution $(70 \mathrm{mM} \mathrm{NaCl}, 5$ $\mathrm{mM} \mathrm{KCl}, 1 \mathrm{mM} \mathrm{CaCl}, 20 \mathrm{mM} \mathrm{MgCl} 2,10 \mathrm{mM} \mathrm{NaHCO}_{3}, 115 \mathrm{mM}$ sucrose, $5 \mathrm{mM}$ trehalose, and $5 \mathrm{mM}$ HEPES) supplemented with $0.423 \mathrm{mM}$ L-cysteine (Calbiochem) 
and $5 \mathrm{U} / \mathrm{mL}$ papain (Worthington) (Note: After L-cysteine addition but before papain addition, the $\mathrm{pH}$ of the solution was recalibrated to 7.4). The brains were then enzymatically digested in the papain solution for 20 minutes before transfer to a $1.5 \mathrm{~mL}$ tube containing $1 \mathrm{~mL}$ of filtered Schneider's medium. Cells were centrifuged at $100 \mathrm{G}$ for 1 minute prior to decantation of Schneider's medium. The solution was replaced with 1 $\mathrm{mL}$ of fresh filtered Schneider's medium. This process was repeated twice before neurons were dissociated by pipetting repeatedly until the solution was homogeneous. The solution with dissociated neurons was then placed on $35 \mathrm{~mm}$ glass bottom dishes (D35-10-0-N; Cellvis) that had been coated with concanavalin A (C2010; SigmaAldrich). Cells were cultured in Schneider's medium supplemented with 10\% FBS, antibiotic/antimycotic solution (A5955; Sigma-Aldrich) and $50 \mu \mathrm{g} / \mathrm{mL}$ of insulin (16634; Sigma-Aldrich) at room temperature in a humidified container at room temperature. After each day in culture, cells were washed twice with PBS to remove any yeast contamination or debris remaining from dissociation.

\section{Live-cell imaging of fly primary neurons}

Live imaging of dissociated neurons was performed as described previously (Wong et al., 2021). Briefly, culture media on plates of dissociated neurons was first replaced with HL-3 $\left(70 \mathrm{mM} \mathrm{NaCl}, 5 \mathrm{mM} \mathrm{KCl}, 1 \mathrm{mM} \mathrm{CaCl}, 20 \mathrm{mM} \mathrm{MgCl}_{2}, 10 \mathrm{mM} \mathrm{NaHCO}_{3}, 115 \mathrm{mM}\right.$ sucrose, $5 \mathrm{mM}$ trehalose, and $5 \mathrm{mM}$ HEPES; $\mathrm{pH} 7.2$, room temperature). For measurements of cytosolic $\mathrm{Ca}^{2+}$, GCaMP5G and tdTomato were sequentially excited at $488 \mathrm{~nm}$ and $561 \mathrm{~nm}$ respectively by an A1 laser confocal microscope with a 40x objective (Nikon). Emission signals at $525 \mathrm{~nm}$ and $595 \mathrm{~nm}$ were recorded. Backgrounds 
were measured from a cell-free ROI. Baselines were established for 1 minute before addition of muscarine $(1 \mathrm{mM})$. Cytosolic $\mathrm{Ca}^{2+}$ transients were evoked by store-depletion with the SERCA inhibitor, thapsigargin, as described. Amplitudes of the GCaMP5G/tdTomato ratio represented cytosolic free $\left[\mathrm{Ca}^{2+}\right] .>50$ cells from a minimum of 5 independently conducted experiments for each condition were used for the calculations.

PercevalHR signals were recorded by measuring the ratio of fluorescence emissions at $525 \mathrm{~nm}$ sequentially excited at $487.5 \mathrm{~nm}$ and $407.8 \mathrm{~nm}$. An A1R laser confocal microscope with 40x objective (Nikon) was used for measurement. Background emission signals were measured from a cell-free ROI. Baselines were established for 1 minute before addition of muscarine $(1 \mathrm{mM})$. For cells subjected to depolarization, the bath was replaced with high $\left[\mathrm{K}^{+}\right](52 \mathrm{mM}) \mathrm{HL}-3$. Muscarine $(1 \mathrm{mM}), 2-\mathrm{DG}(10 \mathrm{mM})$, and oligomycin A (10 $\mu \mathrm{M})$ were added as needed and signals were recorded. Amplitudes of the emission ratio represented the cytosolic $[A T P] /[A D P]$ ratio (Tantama et al., 2013; Wong et al., 2021). Data were quantified as change in the PercevalHR ratio over the baseline prior to the addition of the drug. For this quantification, we used custom $\mathrm{R}$ code to calculate the integrated change (i.e., area under the curve using the AUC function in R) per unit time. $>80$ cells from a minimum of 3-4 independently conducted experiments for each condition were used for the calculations.

\section{Analysis of fly lifespan}


Newly eclosed adult flies were collected and transferred to vials containing standard fly food $\left(\leq 15\right.$ flies per vial). Flies were kept at room temperature $\left(\sim 21^{\circ} \mathrm{C}\right)$ and transferred to new vials twice per week. Dead flies at the bottom of the old vials were counted after each transfer until all the animals in a cohort died.

\section{Statistical analyses}

We used either a parametric or a nonparametric test of statistical significance on the basis of whether the data were normally distributed. Multiple comparisons were made by ANOVA. R, Excel (Microsoft), and Prism 8 (GraphPad) were used for statistical analyses. We used also used Prism for curve fitting. Custom R code used for quantifying data is available upon request. Statistical significance was defined as a $P<$ 0.05. $P$-values were shown on the figures as asterisks: ${ }^{*}, P<0.05 ;{ }^{* *}, P<0.01$; ${ }^{* *}, P<$ $0.001 ;{ }^{* * *}, P<0.0001$. Lifespan (Kaplan-Meier) curves were generated using Prism 8. We used the log-rank (Mantel-Cox) test to determine $P$-values. 


\section{References Cited}

Altman DG, Bland JM (2011) How to obtain the P value from a confidence interval. BMJ (Clinical research ed) 343:d2304 Available at:

http://www.ncbi.nlm.nih.gov/pubmed/22803193 [Accessed December 12, 2021].

Anagnostou G, Akbar MT, Paul P, Angelinetta C, Steiner TJ, de Belleroche J (2010)

Vesicle associated membrane protein B (VAPB) is decreased in ALS spinal cord.

Neurobiology of Aging 31:969-985 Available at:

http://www.ncbi.nlm.nih.gov/pubmed/18701194 [Accessed January 4, 2018].

Baratier J, Peris L, Brocard J, Gory-Fauré S, Dufour F, Bosc C, Fourest-Lieuvin A,

Blanchoin L, Salin P, Job D, Andrieux A (2006) Phosphorylation of microtubule-

associated protein STOP by calmodulin kinase II. The Journal of biological

chemistry 281:19561-19569 Available at:

http://www.ncbi.nlm.nih.gov/pubmed/16651267 [Accessed October 4, 2021].

Bloomquist BT, Shortridge RD, Schneuwly S, Perdew M, Montell C, Steller H, Rubin G,

Pak WL (1988) Isolation of a putative phospholipase C gene of Drosophila, norpA, and its role in phototransduction. Cell 54:723-733 Available at:

http://www.ncbi.nlm.nih.gov/pubmed/2457447 [Accessed January 4, 2018].

Boczonadi V, Meyer K, Gonczarowska-Jorge H, Griffin H, Roos A, Bartsakoulia M,

Bansagi B, Ricci G, Palinkas F, Zahedi RP, Bruni F, Kaspar B, Lochmüller H,

Boycott KM, Müller JS, Horvath R (2018) Mutations in glycyl-tRNA-synthetase impair mitochondrial metabolism in neurons. Human Molecular Genetics Available at: http://www.ncbi.nlm.nih.gov/pubmed/29648643 [Accessed April 23, 2018]. 
Borgese N, Navone F, Nukina N, Yamanaka T (2021) Mutant VAPB: Culprit or Innocent Bystander of Amyotrophic Lateral Sclerosis? Contact 4:251525642110225

Available at: http://journals.sagepub.com/doi/10.1177/25152564211022515

[Accessed December 12, 2021].

Brand AH, Perrimon N (1993) Targeted gene expression as a means of altering cell

fates and generating dominant phenotypes. Development (Cambridge, England)

118:401-415 Available at: http://www.ncbi.nlm.nih.gov/pubmed/8223268 [Accessed

February 1, 2018].

Brusich DJ, Spring AM, James TD, Yeates CJ, Helms TH, Frank CA (2018) Drosophila

CaV2 channels harboring human migraine mutations cause synapse

hyperexcitability that can be suppressed by inhibition of a Ca2+ store release

pathway Lu B, ed. PLOS Genetics 14:e1007577 Available at:

https://dx.plos.org/10.1371/journal.pgen.1007577 [Accessed May 6, 2020].

Cárdenas C, Miller RA, Smith I, Bui T, Molgó J, Müller M, Vais H, Cheung K-H, Yang J,

Parker I, Thompson CB, Birnbaum MJ, Hallows KR, Foskett JK (2010) Essential

Regulation of Cell Bioenergetics by Constitutive InsP3 Receptor Ca2+ Transfer to

Mitochondria. Cell 142:270-283 Available at:

http://www.ncbi.nlm.nih.gov/pubmed/20655468 [Accessed January 4, 2018].

Chai A, Withers J, Koh YH, Parry K, Bao H, Zhang B, Budnik V, Pennetta G (2008)

hVAPB, the causative gene of a heterogeneous group of motor neuron diseases in humans, is functionally interchangeable with its Drosophila homologue DVAP-33A at the neuromuscular junction. Human Molecular Genetics 17:266-280 Available at: http://www.ncbi.nlm.nih.gov/pubmed/17947296 [Accessed January 4, 2018]. 
Chaplot K, Pimpale L, Ramalingam B, Deivasigamani S, Kamat SS, Ratnaparkhi GS (2019) SOD1 activity threshold and TOR signalling modulate VAP(P58S) aggregation via reactive oxygen species-induced proteasomal degradation in a Drosophila model of amyotrophic lateral sclerosis. Disease models \& mechanisms 12 Available at: http://www.ncbi.nlm.nih.gov/pubmed/30635270 [Accessed October 4, 2021].

Chouhan AK, Ivannikov M v., Lu Z, Sugimori M, Llinas RR, Macleod GT (2012) Cytosolic Calcium Coordinates Mitochondrial Energy Metabolism with Presynaptic Activity. Journal of Neuroscience 32:1233-1243 Available at:

http://www.ncbi.nlm.nih.gov/pubmed/22279208 [Accessed January 4, 2018].

Coyne AN, Siddegowda BB, Estes PS, Johannesmeyer J, Kovalik T, Daniel SG, Pearson A, Bowser R, Zarnescu DC (2014) Futsch/MAP1B mRNA is a translational target of TDP-43 and is neuroprotective in a Drosophila model of amyotrophic lateral sclerosis. The Journal of neuroscience $\square$ : the official journal of the Society for Neuroscience 34:15962-15974 Available at:

http://www.ncbi.nlm.nih.gov/pubmed/25429138 [Accessed October 5, 2021].

Daniels RW, Rossano AJ, Macleod GT, Ganetzky B (2014) Expression of multiple transgenes from a single construct using viral 2A peptides in Drosophila. PloS one 9:e100637 Available at: http://www.ncbi.nlm.nih.gov/pubmed/24945148 [Accessed September 27, 2021].

De Vos KJ, Mórotz GM, Stoica R, Tudor EL, Lau K-F, Ackerley S, Warley A, Shaw CE, Miller CCJ (2012) VAPB interacts with the mitochondrial protein PTPIP51 to 
regulate calcium homeostasis. Human Molecular Genetics 21:1299-1311 Available at: http://www.ncbi.nlm.nih.gov/pubmed/22131369 [Accessed January 5, 2018].

Deivasigamani S, Verma HK, Ueda R, Ratnaparkhi A, Ratnaparkhi GS (2014) A genetic screen identifies Tor as an interactor of VAPB in a Drosophila model of amyotrophic lateral sclerosis. Biology open 3:1127-1138 Available at: http://www.ncbi.nlm.nih.gov/pubmed/25361581 [Accessed October 4, 2021].

Dietzl G, Chen D, Schnorrer F, Su K-C, Barinova Y, Fellner M, Gasser B, Kinsey K, Oppel S, Scheiblauer S, Couto A, Marra V, Keleman K, Dickson BJ (2007) A genome-wide transgenic RNAi library for conditional gene inactivation in Drosophila. Nature 448:151-156 Available at: http://www.nature.com/articles/nature05954 [Accessed October 3, 2018]. Ding L, Yang X, Tian H, Liang J, Zhang F, Wang G, Wang Y, Ding M, Shui G, Huang X (2018) Seipin regulates lipid homeostasis by ensuring calcium-dependent mitochondrial metabolism. The EMBO Journal 37 Available at: http://www.ncbi.nlm.nih.gov/pubmed/30049710 [Accessed March 30, 2020].

Dong R, Saheki Y, Swarup S, Lucast L, Harper JW, De Camilli P (2016) Endosome-ER Contacts Control Actin Nucleation and Retromer Function through VAP-Dependent Regulation of PI4P. Cell 166:408-423 Available at:

http://www.ncbi.nlm.nih.gov/pubmed/27419871 [Accessed April 23, 2018].

Duchen MR (1992) Ca(2+)-dependent changes in the mitochondrial energetics in single dissociated mouse sensory neurons. The Biochemical journal 283 ( Pt 1):41-50 Available at: http://www.ncbi.nlm.nih.gov/pubmed/1373604 [Accessed January 4, 2018]. 
Dumollard R, Marangos P, Fitzharris G, Swann K, Duchen M, Carroll J (2004) Spermtriggered $[\mathrm{Ca} 2+]$ oscillations and $\mathrm{Ca} 2+$ homeostasis in the mouse egg have an absolute requirement for mitochondrial ATP production. Development 131:30573067 Available at: http://www.ncbi.nlm.nih.gov/pubmed/15163630 [Accessed January 4,2018$]$.

Feeney CJ, Karunanithi S, Pearce J, Govind CK, Atwood HL (1998) Motor nerve terminals on abdominal muscles in larval flesh flies, Sarcophaga bullata: comparisons with Drosophila. The Journal of comparative neurology 402:197-209 Available at: http://www.ncbi.nlm.nih.gov/pubmed/9845243 [Accessed May 14, 2018].

Fergestad T, Bostwick B, Ganetzky B (2006) Metabolic Disruption in Drosophila BangSensitive Seizure Mutants. Genetics 173:1357-1364 Available at: http://www.ncbi.nlm.nih.gov/pubmed/16648587 [Accessed January 4, 2018].

Frere S, Slutsky I (2018) Alzheimer's Disease: From Firing Instability to Homeostasis Network Collapse. Neuron 97:32-58 Available at: http://www.ncbi.nlm.nih.gov/pubmed/29301104 [Accessed January 4, 2018].

Gögel S, Wakefield S, Tear G, Klämbt C, Gordon-Weeks PR (2006) The Drosophila microtubule associated protein Futsch is phosphorylated by Shaggy/Zeste-white 3 at an homologous GSK3 $\beta$ phosphorylation site in MAP1B. Molecular and Cellular Neuroscience 33:188-199 Available at:

http://www.ncbi.nlm.nih.gov/pubmed/16949836 [Accessed July 31, 2019].

Gomez-Suaga P, Paillusson S, Stoica R, Noble W, Hanger DP, Miller CCJ (2017) The ER-Mitochondria Tethering Complex VAPB-PTPIP51 Regulates Autophagy. 
Current Biology 27:371-385 Available at:

http://www.ncbi.nlm.nih.gov/pubmed/28132811 [Accessed January 5, 2018].

Homyk T, Sheppard DE (1977) Behavioral Mutants of DROSOPHILA

MELANOGASTER. I. Isolation and Mapping of Mutations Which Decrease Flight Ability. Genetics 87:95-104 Available at:

http://www.ncbi.nlm.nih.gov/pubmed/17248760 [Accessed May 10, 2018].

Hua R, Cheng D, Coyaud É, Freeman S, Di Pietro E, Wang Y, Vissa A, Yip CM, Fairn GD, Braverman N, Brumell JH, Trimble WS, Raught B, Kim PK (2017) VAPs and ACBD5 tether peroxisomes to the ER for peroxisome maintenance and lipid homeostasis. The Journal of Cell Biology 216:367-377 Available at:

http://www.ncbi.nlm.nih.gov/pubmed/28108526 [Accessed April 23, 2018].

Hummel T, Krukkert K, Roos J, Davis G, Klämbt C (2000) Drosophila Futsch/22C10 is a MAP1B-like protein required for dendritic and axonal development. Neuron 26:357370 Available at: http://www.ncbi.nlm.nih.gov/pubmed/10839355 [Accessed April 22, 2018].

Ivannikov MV, Macleod GT (2013) Mitochondrial Free Ca2+ Levels and Their Effects on Energy Metabolism in Drosophila Motor Nerve Terminals. Biophysical Journal 104:2353-2361 Available at: http://www.ncbi.nlm.nih.gov/pubmed/23746507 [Accessed January 4, 2018].

Joiner MIA, Griffith LC (1997) CaM kinase II and visual input modulate memory formation in the neuronal circuit controlling courtship conditioning. The Journal of neuroscience $\square$ : the official journal of the Society for Neuroscience 17:9384-9391 
Available at: http://www.ncbi.nlm.nih.gov/pubmed/9364084 [Accessed April 22, 2018].

Kamemura K, Chen C-A, Okumura M, Miura M, Chihara T (2021) Amyotrophic lateral sclerosis-associated Vap33 is required for maintaining neuronal dendrite morphology and organelle distribution in Drosophila. Genes to cells $\square$ : devoted to molecular \& cellular mechanisms 26:230-239 Available at:

http://www.ncbi.nlm.nih.gov/pubmed/33548103 [Accessed October 4, 2021].

Kanekura K, Nishimoto I, Aiso S, Matsuoka M (2006) Characterization of Amyotrophic Lateral Sclerosis-linked P56S Mutation of Vesicle-associated Membrane Proteinassociated Protein B (VAPB/ALS8). Journal of Biological Chemistry 281:3022330233 Available at: http://www.ncbi.nlm.nih.gov/pubmed/16891305 [Accessed January 4,2018$]$.

Kun-Rodrigues C, Ganos C, Guerreiro R, Schneider SA, Schulte C, Lesage S, Darwent L, Holmans P, Singleton A, Bhatia K, Bras J, Bras J (2015) A systematic screening to identify de novo mutations causing sporadic early-onset Parkinson's disease. Human Molecular Genetics 24:6711-6720 Available at: http://www.ncbi.nlm.nih.gov/pubmed/26362251 [Accessed April 23, 2018].

Landers JE, Leclerc AL, Shi L, Virkud A, Cho T, Maxwell MM, Henry AF, Polak M, Glass JD, Kwiatkowski TJ, Al-Chalabi A, Shaw CE, Leigh PN, Rodriguez-Leyza I, McKenna-Yasek D, Sapp PC, Brown RH (2008) New VAPB deletion variant and exclusion of VAPB mutations in familial ALS. Neurology 70:1179-1185 Available at: http://www.ncbi.nlm.nih.gov/pubmed/18322265 [Accessed January 4, 2018]. 
Le Masson G, Przedborski S, Abbott LF (2014) A Computational Model of Motor Neuron Degeneration. Neuron 83:975-988 Available at: http://www.ncbi.nlm.nih.gov/pubmed/25088365 [Accessed January 4, 2018].

Lin G, Mao D, Bellen HJ (2017) Amyotrophic Lateral Sclerosis Pathogenesis Converges on Defects in Protein Homeostasis Associated with TDP-43 Mislocalization and Proteasome-Mediated Degradation Overload. Current topics in developmental biology 121:111-171 Available at: http://www.ncbi.nlm.nih.gov/pubmed/28057298 [Accessed November 28, 2021].

Ling S-C, Polymenidou M, Cleveland DW (2013) Converging Mechanisms in ALS and FTD: Disrupted RNA and Protein Homeostasis. Neuron 79:416-438 Available at: http://www.ncbi.nlm.nih.gov/pubmed/23931993 [Accessed January 7, 2018].

Lytton J, Westlin M, Hanley MR (1991) Thapsigargin inhibits the sarcoplasmic or endoplasmic reticulum Ca-ATPase family of calcium pumps. Journal of Biological Chemistry 266:17067-17071.

Mahr A, Aberle H (2006) The expression pattern of the Drosophila vesicular glutamate transporter: A marker protein for motoneurons and glutamatergic centers in the brain. Gene Expression Patterns 6:299-309 Available at: https://www.sciencedirect.com/science/article/pii/S1567133X05001006 [Accessed April 22, 2018].

Mao D, Lin G, Tepe B, Zuo Z, Tan KL, Senturk M, Zhang S, Arenkiel BR, Sardiello M, Bellen HJ (2019) VAMP associated proteins are required for autophagic and lysosomal degradation by promoting a Ptdlns4P-mediated endosomal pathway. 
Autophagy 15:1214-1233 Available at:

http://www.ncbi.nlm.nih.gov/pubmed/30741620 [Accessed October 4, 2021].

Marques VD, Barreira AA, Davis MB, Abou-Sleiman PM, Silva WA, Zago MA, Sobreira C, Fazan V, Marques W (2006) Expanding the phenotypes of the Pro56SerVAPB mutation: Proximal SMA with dysautonomia. Muscle \& Nerve 34:731-739 Available at: http://www.ncbi.nlm.nih.gov/pubmed/16967488 [Accessed January 4, 2018].

McCormack JG, Denton RM (1993) The role of intramitochondrial $\mathrm{Ca}^{2+}$ in the regulation of oxidative phosphorylation in mammalian tissues. Biochemical Society Transactions 21:793-799 Available at: http://biochemsoctrans.org/lookup/doi/10.1042/bst0210793 [Accessed January 4, 2018].

McVicker DP, Millette MM, Dent EW (2015) Signaling to the microtubule cytoskeleton: An unconventional role for CaMKII. Developmental Neurobiology 75:423-434 Available at: http://www.ncbi.nlm.nih.gov/pubmed/25156276 [Accessed April 22, 2018].

Mitne-Neto M, Machado-Costa M, Marchetto MCN, Bengtson MH, Joazeiro CA, Tsuda H, Bellen HJ, Silva HCA, Oliveira ASB, Lazar M, Muotri AR, Zatz M (2011) Downregulation of VAPB expression in motor neurons derived from induced pluripotent stem cells of ALS8 patients. Human Molecular Genetics 20:3642-3652 Available at: https://academic.oup.com/hmg/article-lookup/doi/10.1093/hmg/ddr284 [Accessed November 28, 2021].

Moustaqim-Barrette A, Lin YQ, Pradhan S, Neely GG, Bellen HJ, Tsuda H (2014) The amyotrophic lateral sclerosis 8 protein, VAP, is required for ER protein quality 
control. Human Molecular Genetics 23:1975-1989 Available at:

http://www.ncbi.nlm.nih.gov/pubmed/24271015 [Accessed April 23, 2018].

Nishimura AL, Al-Chalabi A, Zatz M (2005) A common founder for amyotrophic lateral sclerosis type 8 (ALS8) in the Brazilian population. Human Genetics 118:499-500 Available at: http://www.ncbi.nlm.nih.gov/pubmed/16187141 [Accessed January 4, 2018].

Nishimura AL, Mitne-Neto M, Silva HCA, Richieri-Costa A, Middleton S, Cascio D, Kok F, Oliveira JRM, Gillingwater T, Webb J, Skehel P, Zatz M (2004) A Mutation in the Vesicle-Trafficking Protein VAPB Causes Late-Onset Spinal Muscular Atrophy and Amyotrophic Lateral Sclerosis. The American Journal of Human Genetics 75:822831 Available at: http://www.ncbi.nlm.nih.gov/pubmed/15372378 [Accessed January 4,2018$]$.

Oka M, Fujisaki N, Maruko-Otake A, Ohtake Y, Shimizu S, Saito T, Hisanaga S-I, lijima KM, Ando K (2017) Ca2+/calmodulin-dependent protein kinase II promotes neurodegeneration caused by tau phosphorylated at Ser262/356 in a transgenic Drosophila model of tauopathy. Journal of biochemistry 162:335-342 Available at: http://www.ncbi.nlm.nih.gov/pubmed/28992057 [Accessed October 4, 2021].

Paillusson S, Gomez-Suaga P, Stoica R, Little D, Gissen P, Devine MJ, Noble W, Hanger DP, Miller CCJ (2017) a-Synuclein binds to the ER-mitochondria tethering protein VAPB to disrupt $\mathrm{Ca} 2+$ homeostasis and mitochondrial ATP production. Acta Neuropathologica 134:129-149 Available at:

http://www.ncbi.nlm.nih.gov/pubmed/28337542 [Accessed April 23, 2018]. 
Parkes TL, Elia AJ, Dickinson D, Hilliker AJ, Phillips JP, Boulianne GL (1998) Extension of Drosophila lifespan by overexpression of human SOD1 in motorneurons. Nature Genetics 19:171-174 Available at: http://www.ncbi.nlm.nih.gov/pubmed/9620775 [Accessed April 22, 2018].

Pennetta G, Hiesinger PR, Fabian-Fine R, Meinertzhagen IA, Bellen HJ (2002) Drosophila VAP-33A directs bouton formation at neuromuscular junctions in a dosage-dependent manner. Neuron 35:291-306 Available at: http://www.ncbi.nlm.nih.gov/pubmed/12160747 [Accessed April 22, 2018].

Peretti D, Dahan N, Shimoni E, Hirschberg K, Lev S (2008) Coordinated Lipid Transfer between the Endoplasmic Reticulum and the Golgi Complex Requires the VAP Proteins and Is Essential for Golgi-mediated Transport. Molecular Biology of the Cell 19:3871-3884 Available at: http://www.ncbi.nlm.nih.gov/pubmed/18614794 [Accessed April 23, 2018].

Rangaraju V, Calloway N, Ryan TA (2014) Activity-Driven Local ATP Synthesis Is Required for Synaptic Function. Cell 156:825-835 Available at: http://www.ncbi.nlm.nih.gov/pubmed/24529383 [Accessed November 24, 2019]. Ratnaparkhi A, Lawless GM, Schweizer FE, Golshani P, Jackson GR (2008) A Drosophila Model of ALS: Human ALS-Associated Mutation in VAP33A Suggests a Dominant Negative Mechanism Rubinsztein DC, ed. PLoS ONE 3:e2334 Available at: http://www.ncbi.nlm.nih.gov/pubmed/18523548 [Accessed January 4, 2018]. Roos J, Hummel T, Ng N, Klämbt C, Davis GW (2000) Drosophila Futsch regulates synaptic microtubule organization and is necessary for synaptic growth. Neuron 
26:371-382 Available at: http://www.ncbi.nlm.nih.gov/pubmed/10839356 [Accessed April 22, 2018].

Rossano AJ, Chouhan AK, Macleod GT (2013) Genetically encoded pH-indicators reveal activity-dependent cytosolic acidification of Drosophila motor nerve termini in vivo. The Journal of Physiology 591:1691-1706 Available at:

http://www.ncbi.nlm.nih.gov/pubmed/23401611 [Accessed January 4, 2018].

Roulin PS, Lötzerich M, Torta F, Tanner LB, van Kuppeveld FJM, Wenk MR, Greber UF (2014) Rhinovirus Uses a Phosphatidylinositol 4-Phosphate/Cholesterol CounterCurrent for the Formation of Replication Compartments at the ER-Golgi Interface. Cell Host \& Microbe 16:677-690 Available at: http://www.ncbi.nlm.nih.gov/pubmed/25525797 [Accessed April 23, 2018].

Sanhueza M, Zechini L, Gillespie T, Pennetta G (2014) Gain-of-function mutations in the ALS8 causative gene VAPB have detrimental effects on neurons and muscles. Biology Open 3:59-71 Available at: https://journals.biologists.com/bio/article/3/1/59/796/Gain-of-function-mutations-inthe-ALS8-causative [Accessed October 5, 2021].

Selfridge JE, E L, Lu J, Swerdlow RH (2013) Role of mitochondrial homeostasis and dynamics in Alzheimer's disease. Neurobiology of disease 51:3-12 Available at: http://linkinghub.elsevier.com/retrieve/pii/S0969996112000125 [Accessed January 4, 2018].

Şentürk M, Mao D, Bellen HJ (2019) Loss of proteins associated with amyotrophic lateral sclerosis affects lysosomal acidification via different routes. Autophagy 
15:1467-1469 Available at: http://www.ncbi.nlm.nih.gov/pubmed/31032688 [Accessed October 4, 2021].

Smith EF, Shaw PJ, De Vos KJ (2017) The role of mitochondria in amyotrophic lateral sclerosis. Neuroscience Letters Available at:

https://www.sciencedirect.com/science/article/pii/S030439401730544X?via\%3Dihu b [Accessed May 24, 2018].

Stoica R, Paillusson S, Gomez-Suaga P, Mitchell JC, Lau DH, Gray EH, Sancho RM, Vizcay-Barrena G, De Vos KJ, Shaw CE, Hanger DP, Noble W, Miller CC (2016) ALS/FTD-associated FUS activates GSK-3 $\beta$ to disrupt the VAPB-PTPIP51 interaction and ER-mitochondria associations. EMBO reports 17:1326-1342 Available at: http://www.ncbi.nlm.nih.gov/pubmed/27418313 [Accessed January 4, 2018].

Sullivan KMC, Scott K, Zuker CS, Rubin GM (2000) The ryanodine receptor is essential for larval development in Drosophila melanogaster. Proceedings of the National Academy of Sciences 97:5942-5947 Available at: http://www.ncbi.nlm.nih.gov/pubmed/10811919 [Accessed January 4, 2018].

Tantama M, Martínez-François JR, Mongeon R, Yellen G (2013) Imaging energy status in live cells with a fluorescent biosensor of the intracellular ATP-to-ADP ratio. Nature communications 4:2550 Available at: http://www.nature.com/doifinder/10.1038/ncomms3550 [Accessed February 3, 2018]. 
Taylor JP, Brown RH, Cleveland DW (2016) Decoding ALS: from genes to mechanism. Nature 539:197-206 Available at: http://www.ncbi.nlm.nih.gov/pubmed/27830784 [Accessed April 22, 2018].

Tsuda H, Han SM, Yang Y, Tong C, Lin YQ, Mohan K, Haueter C, Zoghbi A, Harati Y, Kwan J, Miller MA, Bellen HJ (2008) The Amyotrophic Lateral Sclerosis 8 Protein VAPB Is Cleaved, Secreted, and Acts as a Ligand for Eph Receptors. Cell 133:963-977 Available at: http://www.ncbi.nlm.nih.gov/pubmed/18555774 [Accessed April 23, 2018].

Venkatesh K, Hasan G (1997) Disruption of the IP3 receptor gene of Drosophila affects larval metamorphosis and ecdysone release. Current biology $\square$ : CB 7:500-509 Available at: http://www.ncbi.nlm.nih.gov/pubmed/9273145 [Accessed October 29, 2018].

Verstreken P, Ly C v, Venken KJT, Koh T-W, Zhou Y, Bellen HJ (2005) Synaptic mitochondria are critical for mobilization of reserve pool vesicles at Drosophila neuromuscular junctions. Neuron 47:365-378 Available at: http://www.ncbi.nlm.nih.gov/pubmed/16055061 [Accessed November 30, 2021].

Viquez NM, Li CR, Wairkar YP, DiAntonio A (2006) The B' protein phosphatase 2A regulatory subunit well-rounded regulates synaptic growth and cytoskeletal stability at the Drosophila neuromuscular junction. The Journal of neuroscience $\square$ : the official journal of the Society for Neuroscience 26:9293-9303 Available at: http://www.ncbi.nlm.nih.gov/pubmed/16957085 [Accessed June 3, 2018]. Wong C-O, Chen K, Lin Y, Chao Y, Duraine L, Lu Z, Yoon W, Sullivan JM, Broadhead GT, Sumner CJ, Lloyd TE, Macleod GT, Bellen HJ, Venkatachalam K (2014) A 
TRPV channel in drosophila motor neurons regulates presynaptic resting $\mathrm{Ca}^{2+}$ levels, synapse growth, and synaptic transmission. Neuron 84.

Wong C-O, Karagas NE, Jung J, Wang Q, Rousseau MA, Chao Y, Insolera R, Soppina P, Collins CA, Zhou Y, Hancock JF, Zhu MX, Venkatachalam K (2021) Regulation of longevity by depolarization-induced activation of PLC- $\beta$-IP3R signaling in neurons. Proceedings of the National Academy of Sciences of the United States of America 118 Available at: http://www.ncbi.nlm.nih.gov/pubmed/33859040 [Accessed May 9, 2021].

Wong C-O, Palmieri M, Li J, Akhmedov D, Chao Y, Broadhead GT, Zhu MX, Berdeaux R, Collins CA, Sardiello M, Venkatachalam K (2015) Diminished MTORC1Dependent JNK Activation Underlies the Neurodevelopmental Defects Associated with Lysosomal Dysfunction. Cell Reports 12.

Woolums BM, McCray BA, Sung H, Tabuchi M, Sullivan JM, Ruppell KT, Yang Y, Mamah C, Aisenberg WH, Saavedra-Rivera PC, Larin BS, Lau AR, Robinson DN, Xiang Y, Wu MN, Sumner CJ, Lloyd TE (2020) TRPV4 disrupts mitochondrial transport and causes axonal degeneration via a CaMKII-dependent elevation of intracellular Ca2. Nature communications 11:2679 Available at: http://www.ncbi.nlm.nih.gov/pubmed/32471994 [Accessed October 4, 2021].

Xu L, Wang X, Zhou J, Qiu Y, Shang W, Liu J-P, Wang L, Tong C (2020) Migamediated endoplasmic reticulum-mitochondria contact sites regulate neuronal homeostasis. eLife 9 Available at: http://www.ncbi.nIm.nih.gov/pubmed/32648543 [Accessed October 4, 2021]. 
Zhao YG, Liu N, Miao G, Chen Y, Zhao H, Zhang H (2018) The ER Contact Proteins VAPA/B Interact with Multiple Autophagy Proteins to Modulate Autophagosome Biogenesis. Current Biology 28:1234-1245.e4 Available at: http://www.ncbi.nlm.nih.gov/pubmed/29628370 [Accessed April 23, 2018]. 


\section{Figure legends}

\section{FIGURE 1. Expression of $v_{a p b^{P 58 S}}$ in Drosophila motor neurons led to significant} changes in presynaptic bouton development at the larval NMJ.

(A-D) Representative confocal images of larval NMJs dissected from animals of the indicated genotypes stained with antibodies against HRP (green) and DLG (magenta). Scale bar shown in (A) on the top left applies to all panels. Please note that in all figures, "UAS-transgene/+" refer to the presence of the noted UAS-transgene construct without a GAL4 driver, and "driver>transgene" refers to the UAS-transgene, whose expression was driven using the driver-GAL4.

(E-F) Bar graphs showing quantification of the larval NMJ bouton numbers (E) and relative bouton area (F) in animals of the indicated genotypes. Values represent mean \pm SEM. ${ }^{* *}, P<0.01 ;{ }^{* * *}, P<0.001 ;{ }^{* * *}, P<0.0001 ;$ n.s., not significant, t-tests with Bonferroni correction. Dots represent values from distinct NMJs.

FIGURE 2. VAPB ${ }^{\mathrm{P5} 8 \mathrm{~S}}$-induced defects in presynaptic bouton development are ameliorated upon concomitant loss of $\mathrm{ER}^{\mathrm{Ca}^{2+}}$ release channels.

(A) Model showing that the development of control NMJs on muscles 6 and 7 of the larval body wall muscles leads to the appearance of numerous small boutons. Animals either expressing $v a p b^{P 58 S}$ in motor neurons or harboring mutations that diminish ER $\mathrm{Ca}^{2+}$ release are characterized by the appearance of fewer, but morphologically larger, boutons. Ostensible similarities in bouton development phenotypes raises the question of genetic interactions between these conditions. Image was created with BioRender.com. 
(B-I) Representative confocal images of larval NMJs dissected from animals of the indicated genotypes stained with antibodies against HRP (green) and DLG (magenta). Scale bar shown in (B) applies to all panels.

(J-N) Bar graphs showing quantification of the larval NMJ bouton numbers (J, L-N) and relative bouton area $(\mathbf{K})$ in animals of the indicated genotypes. Values represent mean \pm SEM. ${ }^{*}, P<0.05 ;{ }^{* *}, P<0.01 ;{ }^{* *}, P<0.001 ;{ }^{* * *}, P<0.0001 ;$ n.s., not significant, paired ttests with Bonferroni correction. Dots represent values from distinct NMJs.

\section{FIGURE 3. CaMKII underlies the alterations in presynaptic bouton development in motor neurons expressing vapb ${ }^{P 58 S}$.}

(A) Model showing that either an increase or decrease in presynaptic $\left[\mathrm{Ca}^{2+}\right]$ can result in Futsch hyperphosphorylation and depolymerization of presynaptic microtubules. Elevated $\left[\mathrm{Ca}^{2+}\right]$ would lead to persistent activation of CaMKII, which could induce Futsch phosphorylation and attendant disruption of presynaptic microtubules leading to the appearance of fewer, but larger, boutons. Decreased expression of ER $\mathrm{Ca}^{2+}$ channels results in lower presynaptic resting $\left[\mathrm{Ca}^{2+}\right]$ and diminished calcineurin activity (Wong et al., 2014), which also results in Futsch phosphorylation and attendant disruption of presynaptic microtubules leading to the appearance of fewer, but larger, boutons. Image was created with BioRender.com.

(B) Representative confocal images of NMJs expressing vapb ${ }^{P 58 S}$ either with or without $C K I I^{a l a}$ as indicated. Samples were stained with antibodies against HRP (green) and Futsch (magenta). White arrowheads point to individual boutons and highlight recovery of Futsch loops in neurons expressing both $v a p b^{P 58 S}$ and $C K I I^{a l a}$. Higher magnification 
images (high-mag) represent the regions shown in the box overlaid on the merged images. Scale bar shown on the top left applies to all panels.

(C-E) Bar graphs showing quantification of the number of Futsch loops per NMJ (C) and larval NMJ bouton numbers (D-E) in animals of the indicated genotypes. Values represent mean \pm SEM. *,$P<0.05 ;{ }^{* *}, P<0.01 ;{ }^{* * *}, P<0.001 ;{ }^{* * * *}, P<0.0001$; n.s., not significant, paired t-tests with Bonferroni correction. Dots represent values from distinct NMJs.

(F) Lifespan of flies of the indicated genotypes. ${ }^{* * *}, P<0.0001$; n.s., not significant, logrank tests with Bonferroni correction.

FIGURE 4. Expression of $\operatorname{vapb}^{P 58 S}$ results in delayed extrusion of cytosolic $\mathrm{Ca}^{2+}$. (A) Representative EJP (left) and paired-pulse EJP (right) traces recorded from larval NMJs isolated from animals expressing $\operatorname{vapb}^{W T}$ (blue trace) or vapb ${ }^{P 5 S}$ (magenta trace) in motor neurons using ok731-GAL4.

(B) Bar graph showing quantification of the EJP amplitudes from the data shown in (A). Values represent mean \pm SEM. n.s., not significant, paired t-tests. Dots represent values from distinct NMJs.

(C) Bar graph showing quantification of the paired-pulse ratio (fractional change in the amplitude of the second EJP to that of the first EJP when the two stimulatory pulses were applied 50ms apart) of the data shown in (A). Values represent mean \pm SEM. *, $P<0.05$, t-tests. Dots represent values from distinct NMJs. 
(D) Bar graph showing quantification of the mini EJP amplitudes. Values represent mean \pm SEM. n.s., not significant, paired t-tests. Dots represent values from distinct NMJs.

(E) Bar graph showing quantification of quantal content (ratio of amplitudes of EJP and mini EJP). Values represent mean \pm SEM. n.s., not significant, paired t-tests. Dots represent values from distinct NMJs.

(F) Model showing that the rates of $\left[\mathrm{Ca}^{2+}\right]$ elevation and extrusion are necessary for maintaining the fidelity of synaptic transmission. Paired-pulse facilitation without a change in the amplitude of the first pulse, as seen in (A), could be explained by $\mathrm{VAPB}^{\mathrm{P} 58 \mathrm{~S}}$ decreasing the rates of $\mathrm{Ca}^{2+}$ extrusion. Image was created with BioRender.com.

(G) Left, traces showing the decay of GCaMP5G/tdTomato ratio after thapsigargin (TG)induced cytosolic $\left[\mathrm{Ca}^{2+}\right]$ elevations in motor neurons dissociated from animals of the indicated genotypes. Values were fit to a $1^{\text {st }}$ order exponential function. Values represent mean \pm SEM of traces from $>50$ neurons of each genotype. Right, box plots showing quantification of half-lives of decay of the signals in individual neurons of the indicated genotypes. ${ }^{*}, P<0.05$, t-tests, Mann-Whitney test. Dots represent values from individual neurons expressing the indicated transgenes.

FIGURE 5. Activity-dependent ATP production and synaptic transmission is diminished in motor neurons expressing vapb ${ }^{P 58 S}$.

(A) Model adapted from Le Masson et al. (Le Masson et al., 2014) showing the role for neuronal ATP in mediating ionic homeostasis. In healthy neurons, ATP derived from 
mitochondrial oxidative phosphorylation (OXPHOS) powers $\mathrm{Ca}^{2+}$ ATPases, such as SERCA and PMCA, to maintain $\mathrm{Ca}^{2+}$ homeostasis, and the $\mathrm{Na}^{+} / \mathrm{K}^{+}$ATPase, which is needed for setting the resting membrane potential and for repolarization of the membrane potential after bouts of depolarization. In ALS neurons, a decrease in mitochondrial ATP production would attenuate the activities of $\mathrm{Ca}^{2+}$ - and $\mathrm{Na}^{+} / \mathrm{K}^{+}-$ ATPases. This would be predicted to set in motion a self-reinforcing "deadly loop" comprised of continuously increasing ATP consumption coupled with diminished ATP availability, $\mathrm{Ca}^{2+}$ dyshomeostasis, and the eventual loss of membrane potential. Image was created with BioRender.com.

(B) Representative traces showing normalized PercevalHR ratio in Drosophila motor neurons coexpressing the indicated transgenes. Values represent mean \pm SEM of traces from 14-15 neurons of each genotype. Arrows indicate treatments.

(C) Box plots showing the integrated change in the PercevalHR ratio per unit time. Median value of zero indicates no change in the PercevalHR ratio (i.e., [ATP]/[ADP] ratio), median values $>0$ denote a net increase in the PercevalHR ratio after the treatment, and median values $<0$ denote a net decrease in the PercevalHR ratio after the treatment. ${ }^{*}, P<0.05 ;{ }^{* *}, P<0.01 ;{ }^{* * *}, P<0.001 ;{ }^{* * *}, P<0.0001$; n.s., not significant. Colored significance values below the box plots show results of one-sample Wilcoxon test for the hypothetical median value of 0 . Significance tests shown on the top represent results of Mann-Whitney tests for comparing median values in the two genotypes.

(D) Traces showing the decay of the PercevalHR ratio after application of oligomycin A (oligoA). The time of oligoA addition was set to 0 . Values were normalized to the 
PercevalHR ratio at the time of oligoA addition, and represent mean \pm SEM of traces from 85-120 neurons of each genotype. Values were also fit to $1^{\text {st }}$ order exponential functions.

(E) Parameters of the fit to $1^{\text {st }}$ order exponential functions from (D). Left, box plot showing the normalized ratio of the plateau and starting $\left(\mathrm{Y}_{0}\right)$ values. Right, box plot showing the normalized half-life of decay. ${ }^{* *}, P<0.01$ and n.s., not significant, ManWhitney tests.

(F) Traces showing EJP amplitudes recorded from NMJs of animals of the indicated genotypes stimulated at $10 \mathrm{~Hz}$ for 10 minutes. Traces connecting filled circles represent raw values that were determined experimentally, and the traces connecting filled squares represent calculated rundowns fit to $1^{\text {st }}$-order exponential decay. Green arrows indicate the onset of decay. $\mathrm{Cl}$, confidence interval; $P$-values for $\mathrm{Cl}$ were calculated as described in the methods. All values represent mean \pm SEM of EJP values recorded from 5 NMJ preparations of each genotype. 
Fig. 1
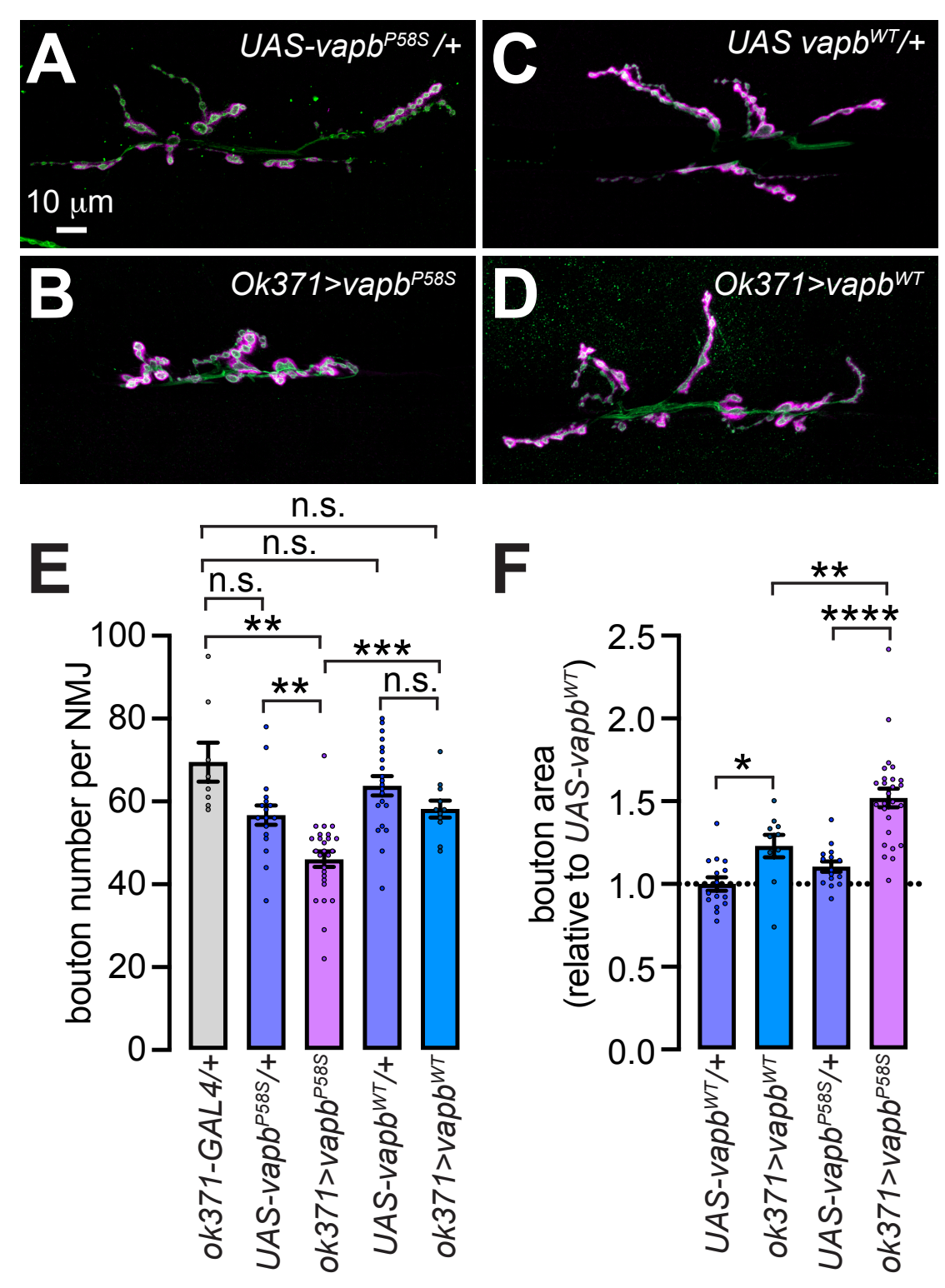
A

NMJ on muscles 6 and 7
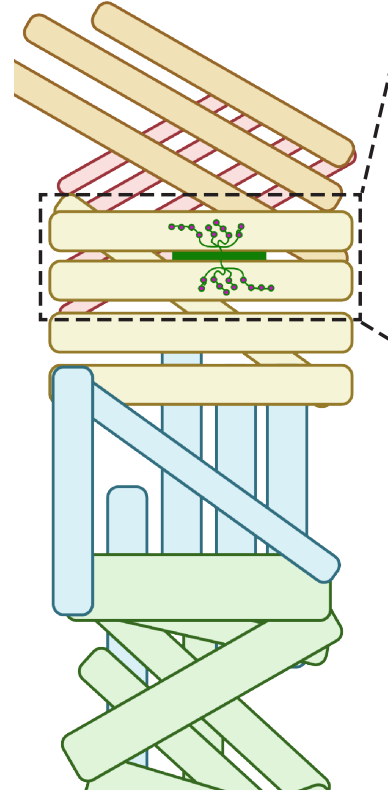

larval body wall muscles
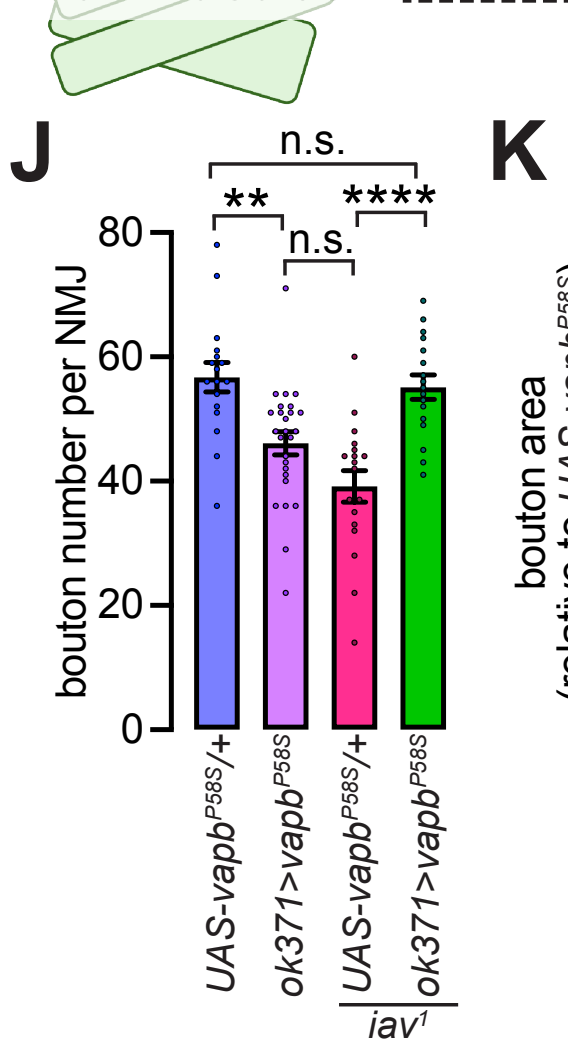

numerous

smaller boutons
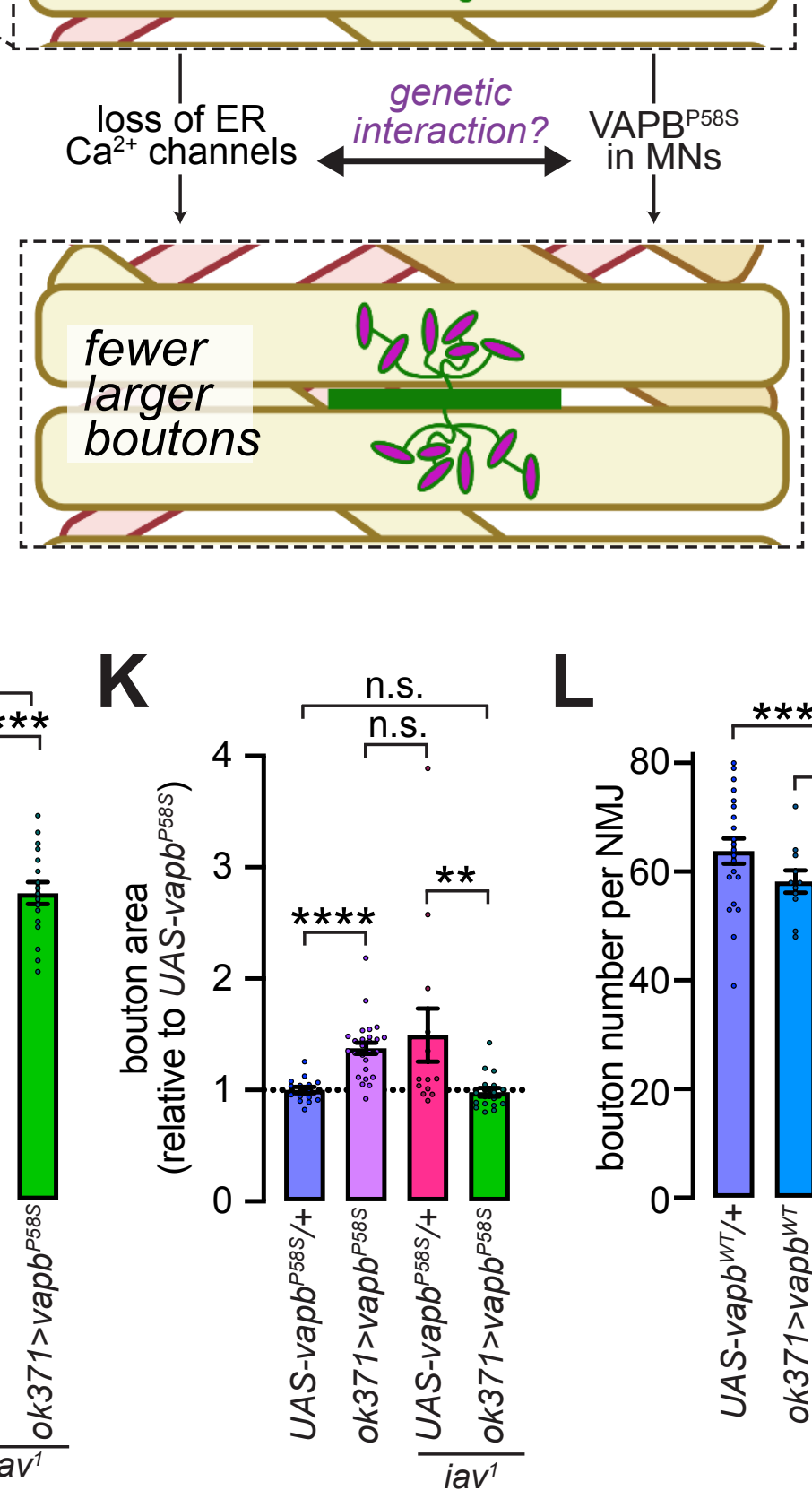

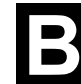

iav $^{1} ; U A S-v a p b^{P 58 S}$

.

$d 42>v_{a p p} b^{P 58 S}+d i c e r$

Fig. 2

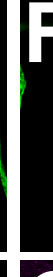

\section{$10 \mu \mathrm{m}$}
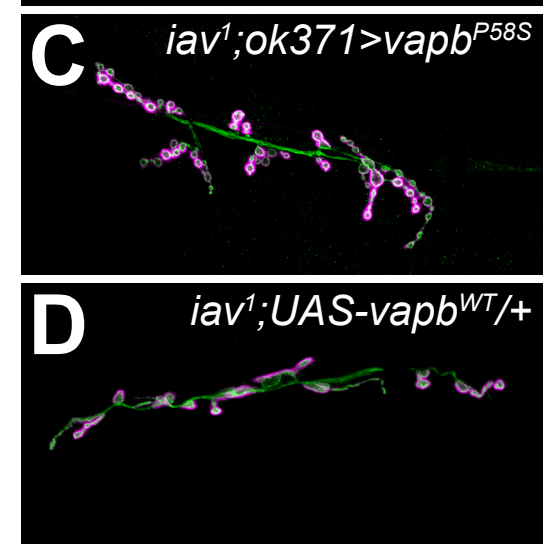

新数
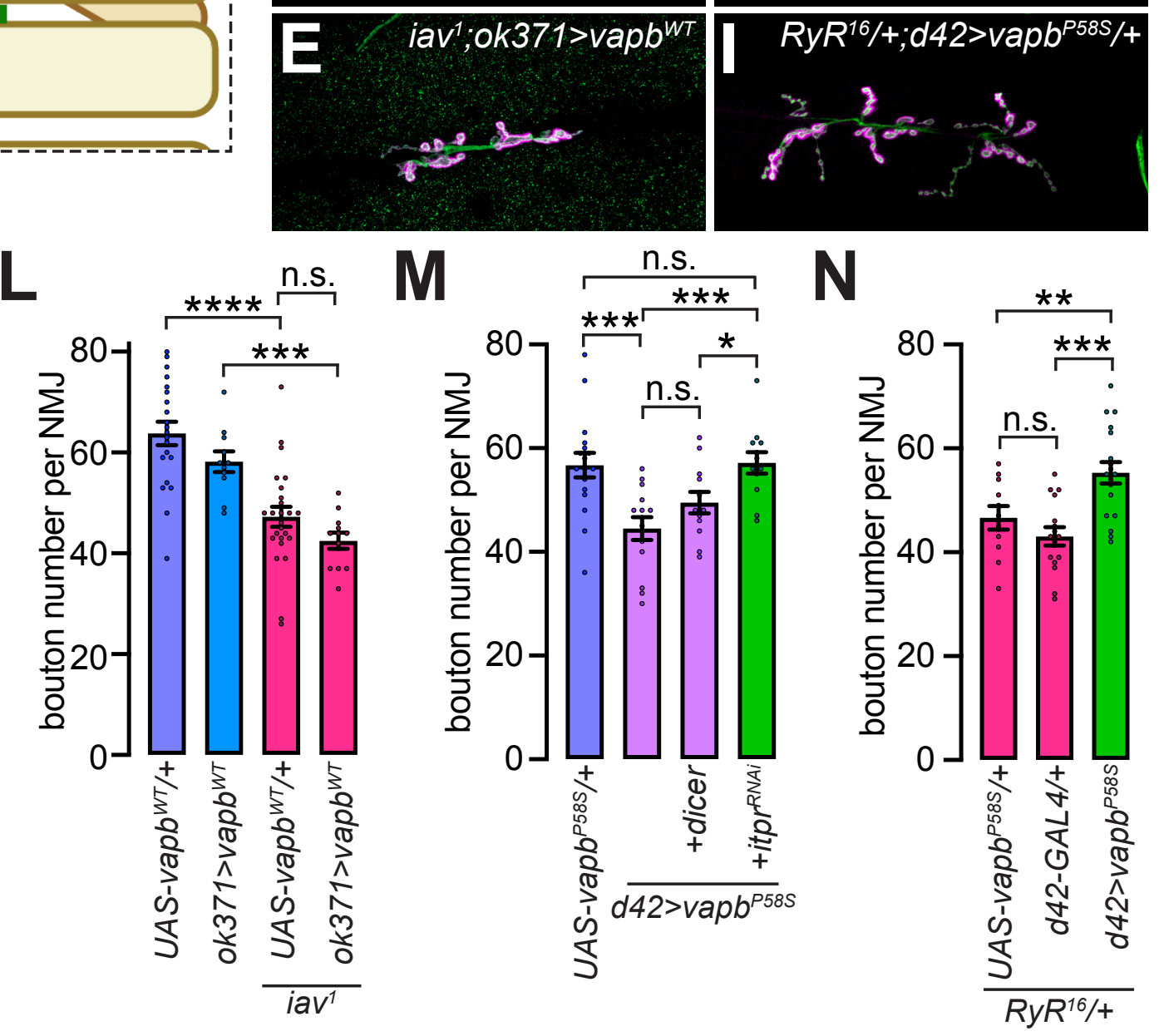

N

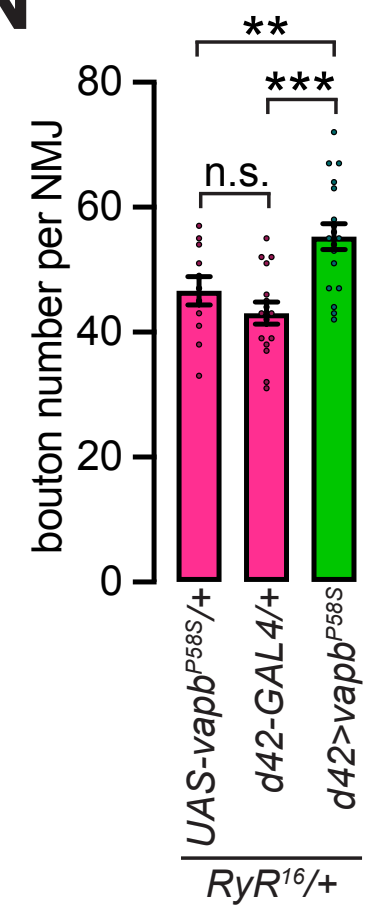


Fig. 3

A polymerized microtubules

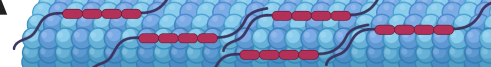

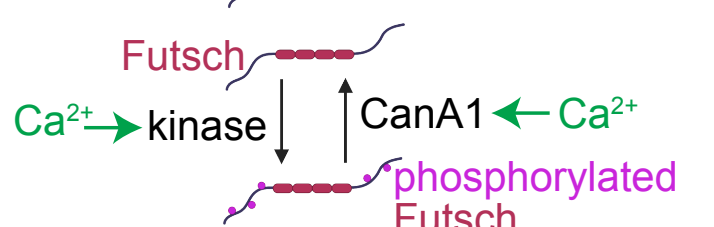

B
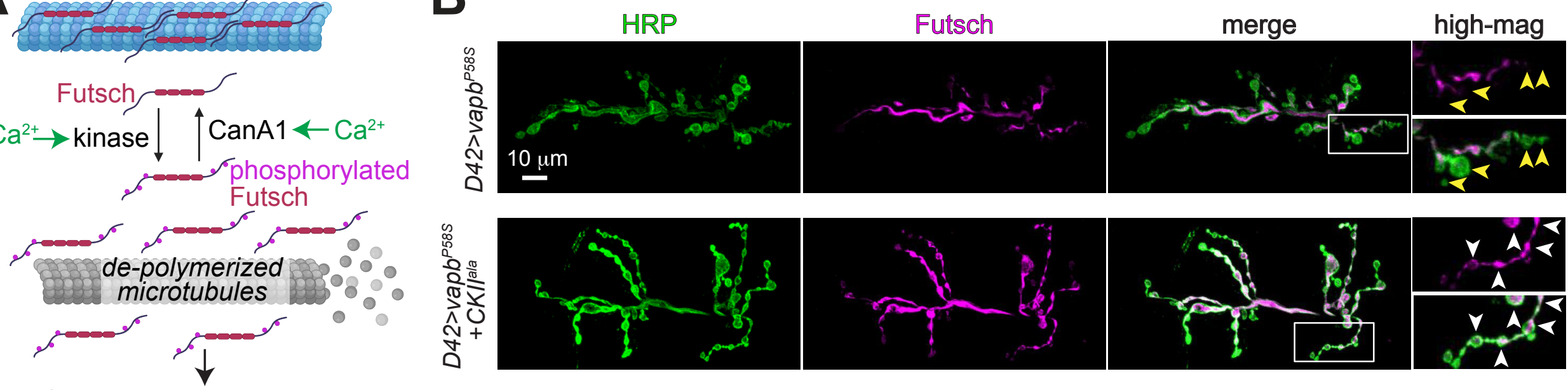

fewer and larger boutons
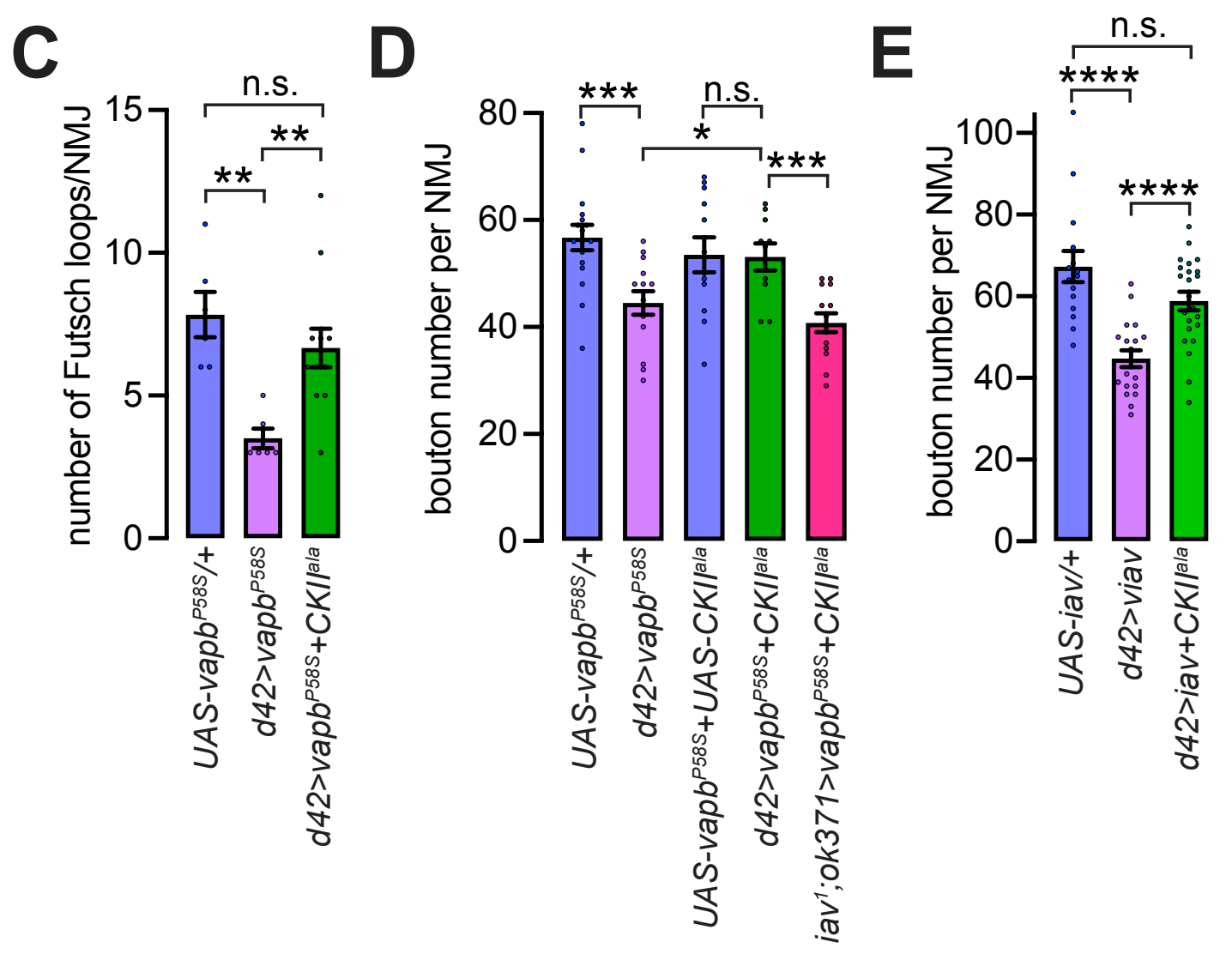
F UAS-vaph ${ }^{p 58 S}+U A S-C K I I^{a l a} * * * *$ d42>vaph ${ }^{\text {P58S }}+$ CKIIlala
d42>vaph

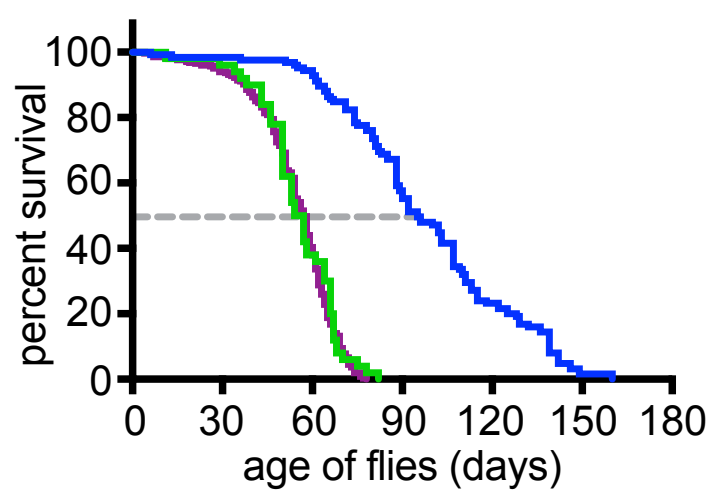



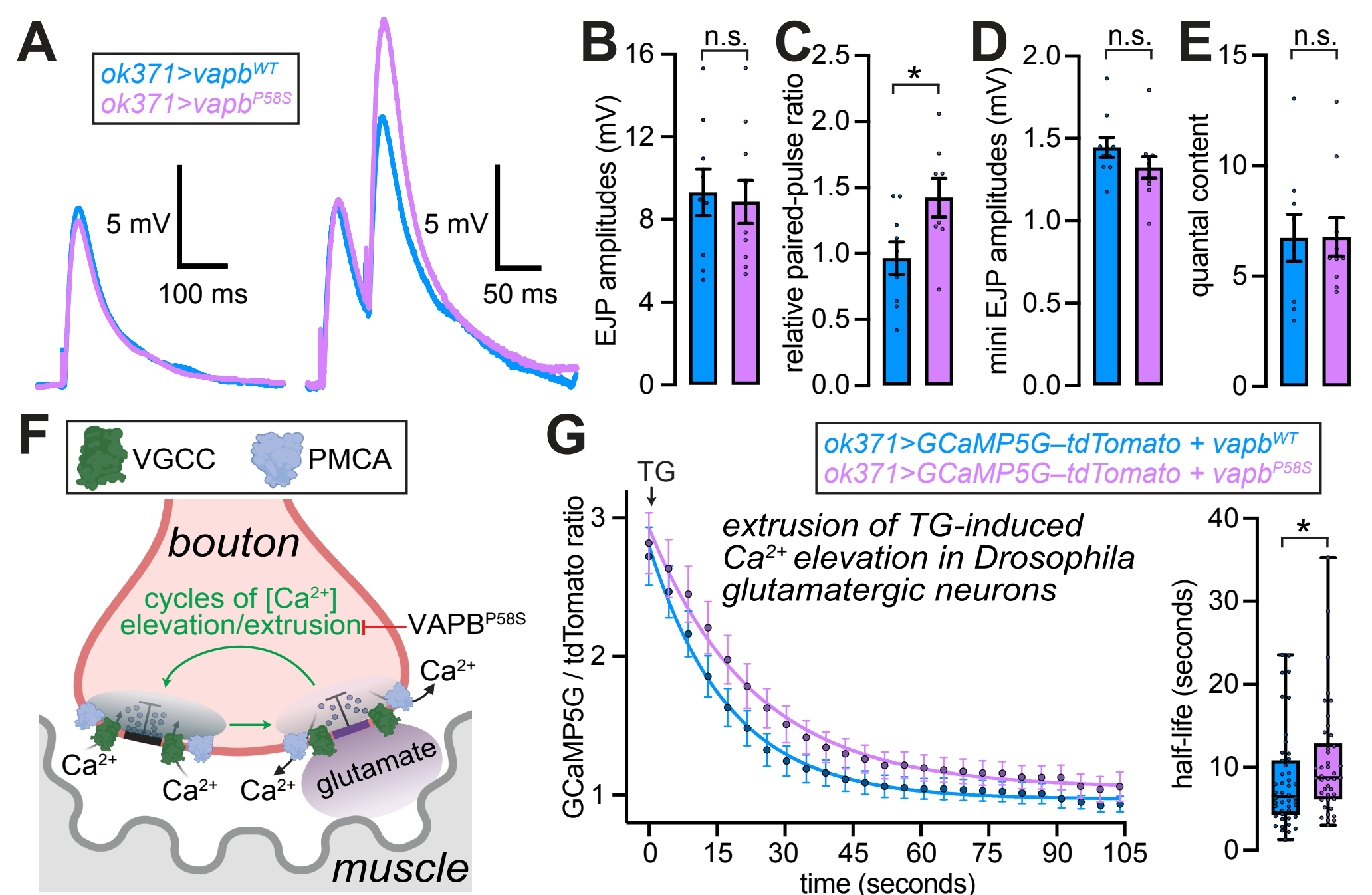

$G$
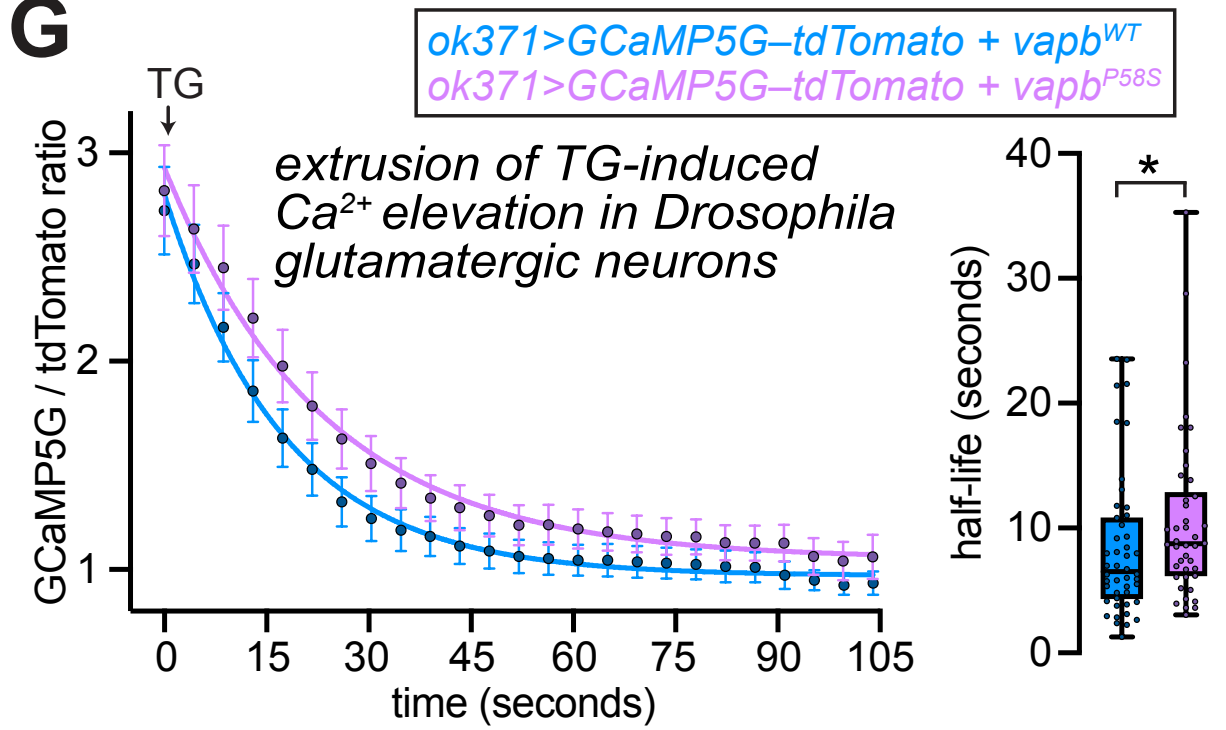


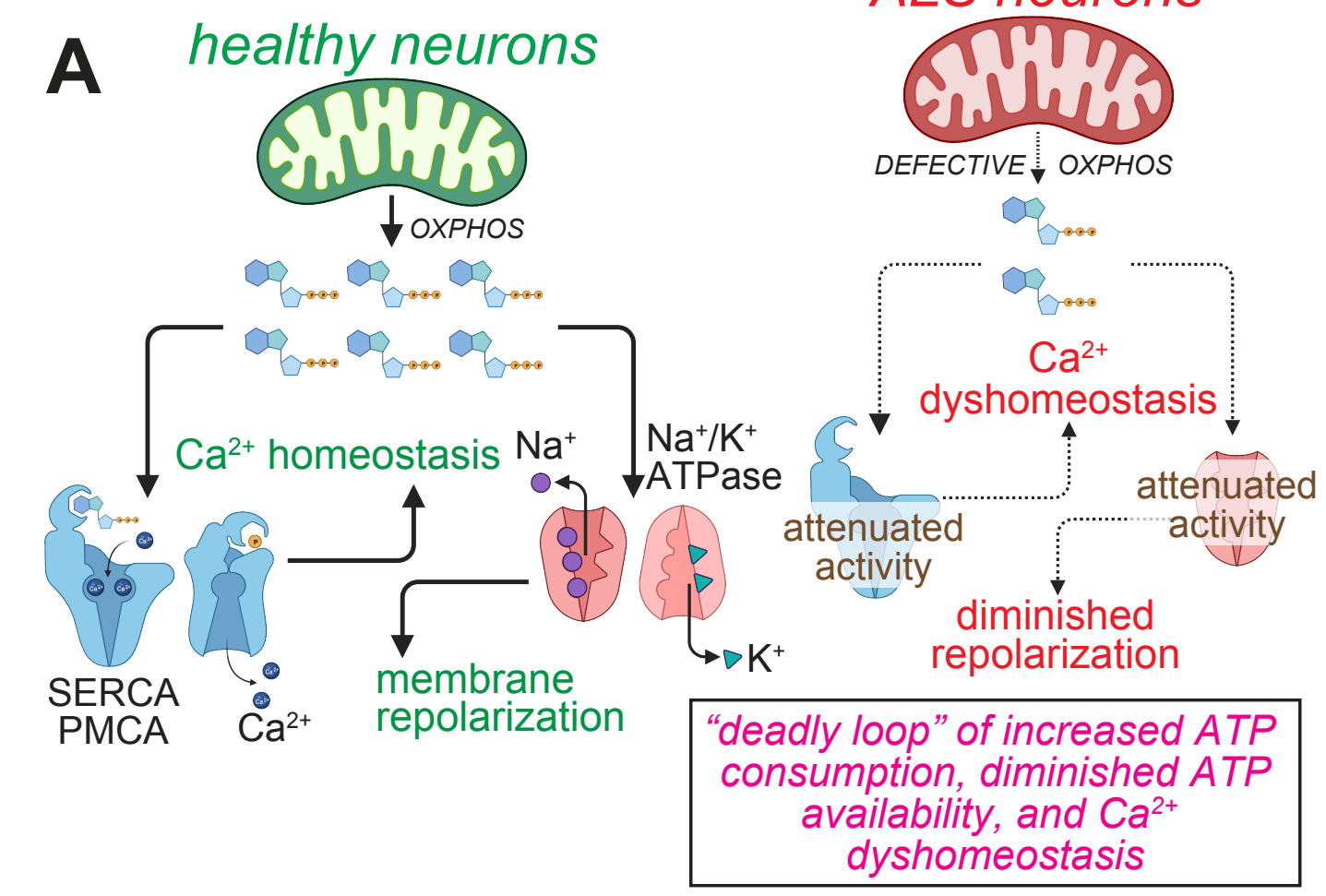

ALS neurons

C

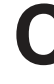

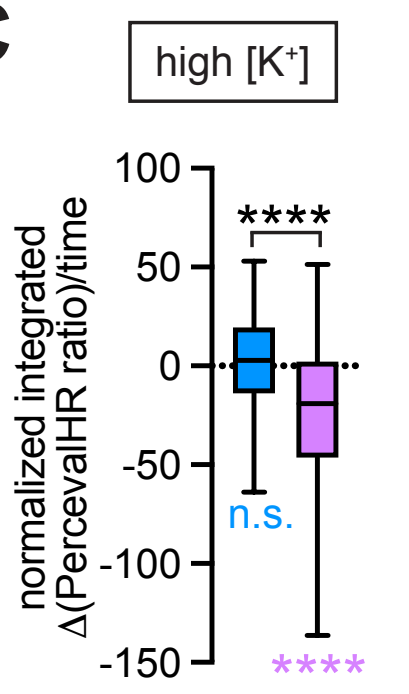
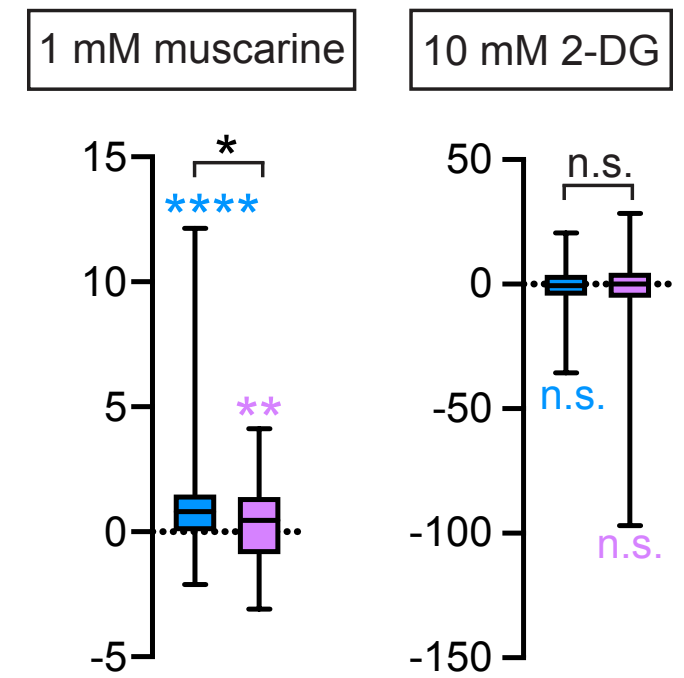

B d42>PercevalHR + vapb $b^{W T}$ d42>PercevalHR + vaphP58S \begin{tabular}{|l|}
\hline 1 - high $\left[\mathrm{K}^{+}\right]$ \\
$2-1 \mathrm{mM}$ muscarine \\
3 - $10 \mathrm{mM} 2-\mathrm{DG}$ \\
$4-10 \mu \mathrm{M}$ oligoA
\end{tabular}

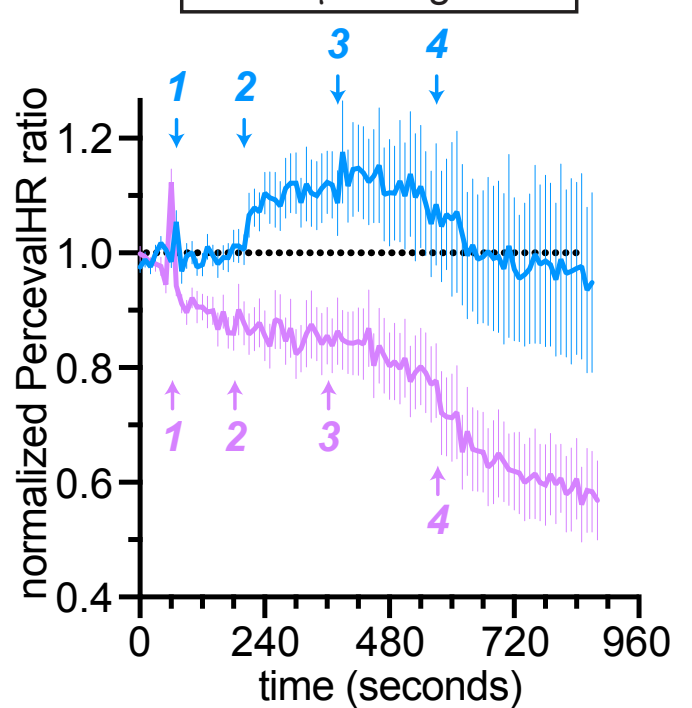

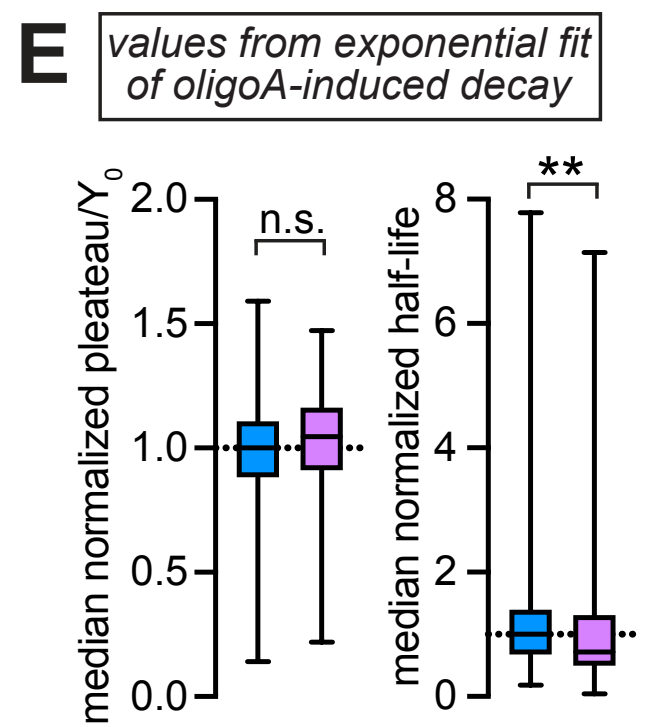
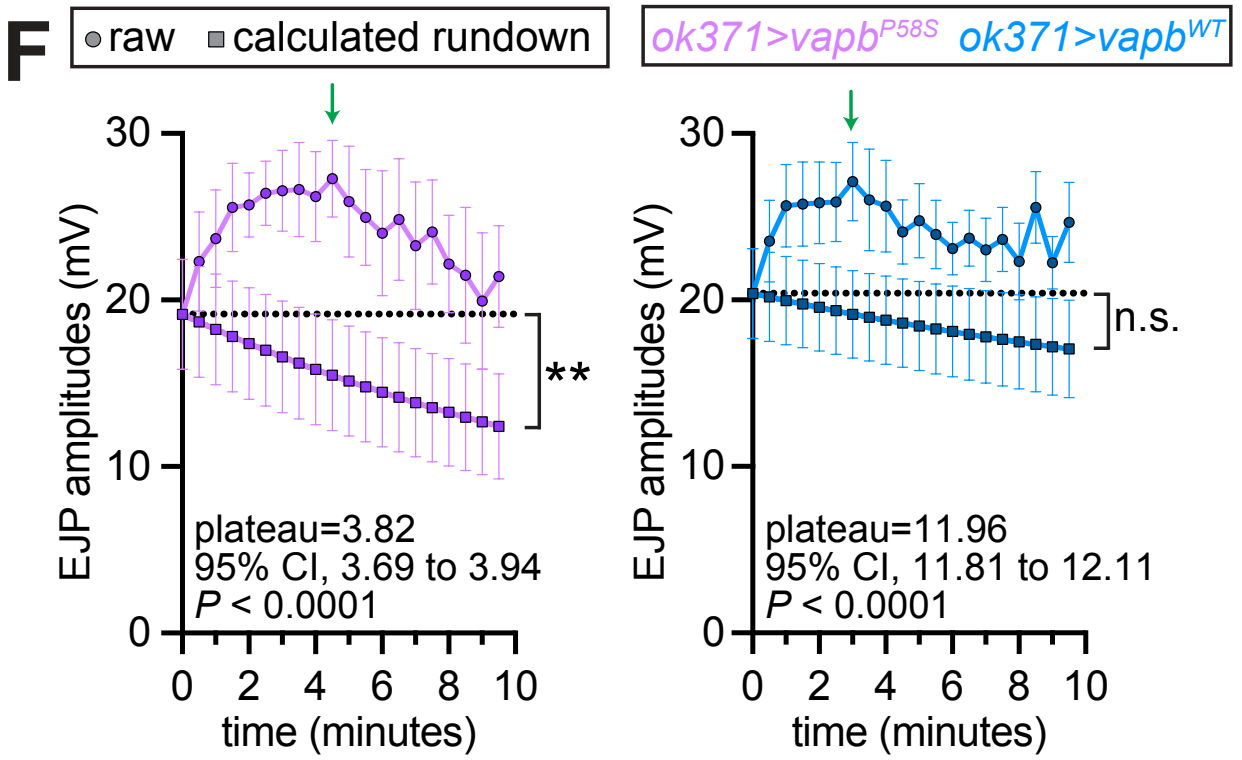

D

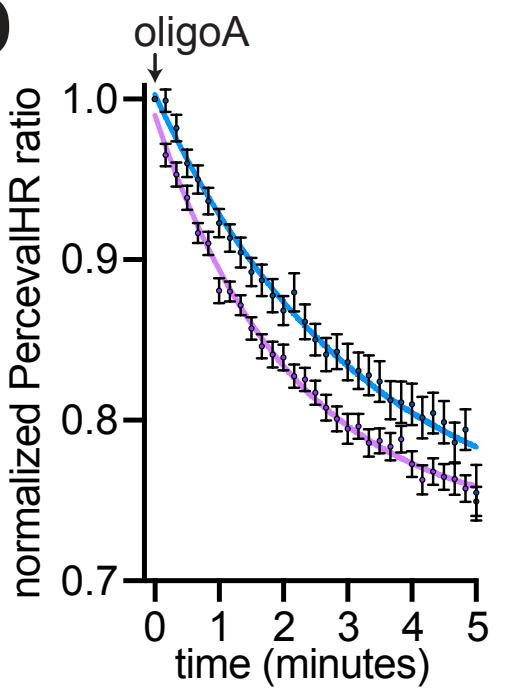

